LA WAFNOE WWTAWCAE NATIONAI EBCAMTOAT

\section{July 2004 Working Group Meeting on Heavy Vehicle Aerodynamic Drag: Presentations, Summary of Comments and Conclusions}

R. McCallen, K. Salari, J. Ortega, P. Castellucci, C. Eastwood, L. DeChant, B. Hassan, F. Browand, D. Arcas, J. Ross, J.T. Heineck, B. Storms, S. Walker, A. Leonard, C. Roy, D. Whitfield, D. Pointer, T. Sofu, R. Englar, R. Funk

August 16, 2004 
This document was prepared as an account of work sponsored by an agency of the United States Government. Neither the United States Government nor the University of California nor any of their employees, makes any warranty, express or implied, or assumes any legal liability or responsibility for the accuracy, completeness, or usefulness of any information, apparatus, product, or process disclosed, or represents that its use would not infringe privately owned rights. Reference herein to any specific commercial product, process, or service by trade name, trademark, manufacturer, or otherwise, does not necessarily constitute or imply its endorsement, recommendation, or favoring by the United States Government or the University of California. The views and opinions of authors expressed herein do not necessarily state or reflect those of the United States Government or the University of California, and shall not be used for advertising or product endorsement purposes. 
This work was performed under the auspices of the U. S. Department of Energy by the University of California, Lawrence Livermore National Laboratory under Contract No. W-7405-Eng-48. 


\title{
July 2004 \\ Working Group Meeting on Heavy Vehicle Aerodynamic Drag: Presentation, Summary of Comments, and Conclusions
}

\author{
Jointly written by \\ Lawrence Livermore National Laboratory \\ Sandia National Laboratories \\ University of Southern California \\ California Institute of Technology \\ NASA Ames Research Center \\ Georgia Tech Research Institute \\ Argonne National Laboratory \\ University of Tennessee Chattanooga
}

\begin{abstract}
A Working Group Meeting on Heavy Vehicle Aerodynamic Drag was held in Portland, Oregon on July 1, 2004. The purpose of the meeting was to provide a summary of achievements, discuss pressing issues, present a general overview of future plans, and to provide a forum for dialogue with the Department of Energy (DOE) and industry representatives. The meeting was held in Portland, because the DOE Aero Team participated in an exclusive session on Heavy Truck Vehicle Aerodynamic Drag at the $34^{\text {th }}$ AIAA Fluid Dynamics Conference and Exhibit in Portland on the morning of July $1^{\text {st }}$, just preceding our Working Group meeting. Even though the paper session was on the last day of the Conference, the Team presented to a full room of interested attendees.

Participating in the Working Group Meeting were representatives from the DOE/Office of Energy Efficiency and Renewable Energy/Office of FreedomCAR \& Vehicle Technologies, Lawrence Livermore National Laboratory (LLNL), Sandia National Laboratories (SNL), NASA Ames Research Center (NASA), University of Southern California (USC), California Institute of Technology (Caltech), Georgia Tech Research Institute (GTRI), Argonne National Laboratory (ANL), University of Tennessee Chattanooga (UTC), Auburn University, NavistarInternational, Freightliner, and PACCAR. This report contains the technical presentations (viewgraphs) delivered at the Meeting, briefly summarizes the comments and conclusions, provides some highlighted items, and outlines the future action items.
\end{abstract}

\section{Project Goals and Future Activities}

Based on discussions at the Meeting, the existing project goals remain unchanged and enhancing interactions with fleet owners and operators was emphasized: 
- Perform heavy vehicle computations to provide guidance to industry,

- Using experimental data, validate computations,

- Provide industry with design guidance and insight into flow phenomena from experiments and computations, and

- Investigate aero devices with emphasis on collaborative efforts with fleet owners and operators.

The following activities were identified and the responsible individuals are indicated:

1) Construct FY05 tasks and budget by early August, determining high priority activities, considering expected budget cuts (Rose M.).

2) Identify chairperson(s) for $2^{\text {nd }}$ International Heavy Vehicle Aero Conference (Fred B.)

3) Establish collaborations with fleet owner and operators.

a) Participate in TMA Conference, Nashville, TN in September (Jim R.).

b) Schedule meetings with owner/operators

i) In California (Rose M.)

ii) In Tennessee (David W.).

c) Contact California Trucking Association and request meeting (Rose M.).

d) Seek guidance from TMA's/Caterpillar's Bob Wessel (Rose M.)

e) Invite fleet owners and operators to attend Working Group Meetings (Rose M.).

4) Develop plan of approach for the computational investigation of underbody flow and the detrimental effects of axles, cross beams, wheels, wheel wells, etc. on aero drag (Kambiz S.).

5) Put conference papers or link to papers on project website, as well as meeting report with viewgraphs (Helen M.).

6) Write white papers/preliminary proposals and seek assistance from Jules and Sid to market them to potential sponsors:

a) Construct white paper on demonstration of major aero device technology for presentation to DOE representative Lee Slezak, DOE (Fred B. and Jason O.).

b) Contract to TMA is almost done. White paper needed that suggests specific devices for track or road testing by industry (Jason O. and Fred B.).

c) White paper for DOT's Duane Perrin and Jim Bertel on splash and spray. May want to include brake cooling (Craig E. and Fred B.).

d) Determine if Freightliner interested in a CRADA activity in underhood flow. Communicate with Tanju Sofu to determine overlap with their CRADA with CAT and coordinate. Write draft/preliminary proposal and give to Jules. (Jim R. and Kambiz S.)

e) Railcars - Identify industry partner. We have been talking to Jim Hart at Johnstown America Corporation in Johnstown, PA, but Jules recommends talking to EMD and GE. Get the contact names from Jules. Construct a draft/preliminary proposal and give to Jules. (Kambiz S. and Jim R.)

7) Schedule and lead a series of conference calls on computational effort, to enhance interactions and cooperation between organizations and address the ideas raised at the July $1^{\text {st }}$ Meeting (Rose M.). 
8) Encourage Team to submit abstracts to APS Fluid Dynamics meeting in Nov. '04 in Seattle (abstracts due Aug $6^{\text {th }}$ ). If enough Team members participate, schedule lunch get together at conference (Helen M.)

9) Continue interactions with large number of device designers and builders that solicit information, in hopes that some will succeed (Rose M.).

10) Investigate Tennessee Valley Authority (TVA) Test Track as a possible test site (David W.).

\section{Meeting Summary}

In this section, we briefly review the major results presented and discussed at the meeting, with a focus on new information not previously presented. See attached viewgraphs for additional results and details.

\section{Introduction}

The meeting began with an introduction by Rose McCallen. Rose explained that the meeting would consist of a very brief presentation to introduce the 3 topics for discussion:

- Achievements,

- Main Issues, and

- Path Forward.

Informal discussions followed each presentation (see agenda at end of this report, before the viewgraphs). Summaries of the last two topics were presented so that conclusions may be established. The highlights of the discussions are presented below and details are provided in the attached summary viewgraphs.

The DOE Program Lead, Sid Diamond, followed the introduction with a discussion on the anticipated budget for FY05 and some insightful information. Considerably less money is expected in FY05 in comparison to FY04. A 20\% budget cut is projected.

Sid is considering the formation of a committee to address the issue of aero devices and their maintenance, initial cost, and durability. He raised the question, "Do we bring in 'practical' mechanical engineers?" Sid acknowledged the importance of continued long-term efforts in computational fluid dynamics and the near-term influences of testing of concepts on vehicles, but he also envisions a parallel path in 'operation activities'.

The DOE Program representative, Jules Routbort, also provided information on the budget. $\mathrm{He}$ requested a summary of prioritized tasks and budget from the Team by mid August. Jules also mentioned that chairpersons for a $2^{\text {nd }}$ International Conference on Heavy Vehicle Aerodynamics are needed. Just as with the $1^{\text {st }}$ International Conference held in December 2002 and chaired by Team members Fred Browand, Jim Ross, and Rose McCallen, this second conference would have Engineering Conferences International (previously known as United Engineering Foundation) and 
DOE sponsorship. Jules requested that Rose McCallen, Fred Browand, and Tony Leonard, identify potential chairpersons for this conference.

\section{Achievements}

Attached are the viewgraphs presented by Jim Ross, providing an overview of the Program accomplishments. In summary, the Program has demonstrated several concepts and devices which meet the $25 \%$ drag reduction goal. Specific devices have addressed base, gap, and underbody drag reduction. Use of a simple base flap at the trailing edge of the trailer, side extenders or splitter plate at the tractor-trailer gap, and a skirt or a simple short underbody wedge should provide drag reduction exceeding $25 \%$. At highway speeds, fuel savings around $12 \%$ should be recognized for a $25 \%$ reduction in drag. This would represent a savings of $\$ 3$ billion/year in the United States.

The highly successful testing program has provided detailed data for computational validation, guidance on device concepts, and established wind-tunnel testing guidelines. The detailed data exceeds what is typically available for careful code validation in a relatively complex flow and is thus of interest to the general fluid dynamics/aerodynamics research and development community. The state-of-the-art in Particle Image Velocimetry (PIV) was significantly advanced in the efforts at the NASA wind tunnels. With the Ground Transportations System (GTS) model in the 7-ft $x 10-\mathrm{ft}$ wind tunnel, NASA succeeded in being one of the first to use a threedimensional (3D) PIV system in a production wind tunnel. To use PIV in the 12-ft pressure wind tunnel with the Generic Conventional Model (GCM), a new and innovative approach that provided remote control of the PIV system was developed. With this remote system, blowdown of the tunnel was not necessary to position cameras. NASA's is now recognized as having world class capabilities in 3D PIV because of the DOE Heavy Vehicle Aerodynamics Program.

The computational flow modeling has provided guidance in model definition, mesh refinement, and choice of turbulence model for heavy vehicles. Computations have been used for both the evaluation of flow physics and to guide the conceptual design of devices. For example, it was demonstrated computationally that a splitter plate that partially closes the tractor-trailer gap is adequate to maintain the desired reduced drag, symmetric flow condition and avoid gap blow through. Previous designs assumed that full gap closure from the tractor to the trailer was necessary.

The Program has successfully established industry contacts and collaborations and international recognition in the academic community. The $1^{\text {st }}$ International Conference on the Aerodynamics of Heavy Vehicles: Trucks, Busses and Trains, which was lead by the DOE Aero Team, attracted world renowned researchers and developers from academia, along with significant industry interest and participation. It should also be emphasized that by combining the best of academia and government lab capabilities, technical developments have been leveraged across programs within DOE Labs, NASA, and university programs, while delivering the DOE Heavy Vehicle Program milestones. Examples are the progress in the state-of-the-art in 3D PIV, advances in 
turbulence modeling with the use of hybrid RANS and LES models for efficient and accurate flow modeling, and the use of broadcast fuel rates during real-time, full-scale testing.

Jim's presentation of achievements was followed by a more extensive discussion session than expected. Viewgraphs summarizing the discussion were not constructed, but the following mentions some important comments.

During the discussion session, one of the industry participants mentioned that computational simulation of underbody flow with realistic details is of interest. It was recognized that the exposed axles, cross beams, wheels, wheel wells, etc. contribute to aerodynamic drag and reduce vehicle performance.

Sid Diamond mentioned that we should include in the Program achievements our Team's many publications and record-of-inventions or patents that have resulted from the DOE Heavy Vehicle Program work. Sid also emphasized the importance of leveraging our Program work and seeking funding from other agencies, especially during the expected reduction in funding for the coming year. He encourages the Team to pursue funding to continue our successful investigation of railcar aerodynamics and to further pursue possibilities in the typical, yet still in need, aircraft commercial industry and military applications.

\section{Main Issues}

Attached are the viewgraphs presented by Kambiz Salari, providing a summary of the program's current issues for discussion. Fred Browand, who facilitated the discussion, also presented several viewgraphs on the related topic of 'Design Guidance for Heavy Vehicles \& Aero Devices'. These added viewgraphs are attached, along with the summary viewgraphs constructed and presented by Jason Ortega.

In summary, the specific topic presented was the desire to 'adequately capture reality for design guidance of heavy vehicles and aero devices'. The topic was broken down into the following four issues for discussion:

- Model Scales,

- Model Fidelity,

- Operational Environment, and

- Implementation of Drag-Reducing Aero-Devices.

In Kambiz's topic introduction and in Fred's added viewgraph presentation, they offered background on the improvements in model fidelity. The question was raised as to the importance of improving model fidelity to capture the 'realistic' performance of aero devices. Should rotating wheels, wheel wells, flow through engine, detailed underbody, and even accessories, such as mirrors, wipers, and grab bars be included in wind tunnel testing or is road or track testing recommended? As for computational modeling, should the use of higher fidelity models that include flow through engines and rotating wheels be pursued? Specifically what results are needed to convince fleet owners and operators to use aero-devices? If the issue is the need to broadcast 
information, how do we collectively take the story to fleet owners? The fact is that even though trailer mounted aero devices can, without question, provide significant drag reduction, they are not being used. The following summarizes the opinions of the participants as to why the fleet owners and operators are not using the trailer devices and what can be done to encourage the use of drag reducing technology.

The experiments with the simple GTS geometry were extremely useful in making available needed data for code validation. As a result, clear guidelines and accuracy expectations have been provided for steady RANS modeling, which is the turbulence modeling approach typically used by industry. The GCM geometry provided higher model fidelity and was more representative of a modern tractor trailer. The GCM was utilized to evaluate several aero devices supplying conceptual design guidance. Most impressive are the detailed data at full-scale Reynolds number representative of highway speeds. These experiments make available elucidating information of heavy vehicle flow physics and provide expected accuracy for model scaling, as requested by industry.

Investigations of the integrated vehicle system with higher fidelity were recommended. The industry representatives (tractor manufacturers) provided a prioritized list of what they believe is needed to improve vehicle design. Through enhanced experiments and computations, the characterization of

- Flow through engine

- Underbody flow

- Rotating wheels

- Reynolds (Re) number effects

is desired. Computational and experimental investigations with high fidelity models or full-scale vehicle geometries with integrated components are of interest. The industry representatives also emphasized that cost effective designs are needed to get the aero devices on the road. Not many of the ready-to-market devices can recoup costs. Another related topic mentioned was acoustics. Reducing noise inside or outside the cab produced by the vehicle flow characteristics is of interest and is tied to the list of priority items.

Improving or controlling engine flow for enhanced cooling, while maintaining or improving aerodynamic vehicle drag is of highest importance to the tractor manufacturers because of new EPA emission requirements. The requirements that take effect in January 2007 could significantly increase fuel use by as much as $30 \%$.

Several Team members have investigated underbody flow and agree with the tractor manufacturers in its placement as a high priority item for drag reduction and the need for flow control in this area. It is believed that the underbody flow and rotating wheels are tied to the issue of directing flow to enhance brake cooling while reducing drag. Brakes are currently under designed and are operating often at performance limits. Reducing drag may over tax brakes. There is also concern that some aero devices may direct flow away from brakes, providing less cooling and thus, lowering performance and increasing rate of brake wear. 
Reynolds number effects are still a high priority item for the tractor manufacturers. The GCM experiments in the 12-ft Pressure Wind Tunnel provided valuable information on Re effects for full vehicle aero and devices, but more is desired. It was suggested that further testing be done with higher fidelity models or with full-scale vehicles. Unfortunately, the NASA 12-ft PWT is no longer available for further Re studies and comparable facilities are not available in the United States.

In relation to model fidelity and the impact of relatively small scale characteristics, it was mentioned that the replacement of mirrors with video, can improve fuel economy by almost $2 \%$, and that wide single tires can improve fuel economy by as much as $3.5 \%$ over dual tires. An industry representative explained the fleet owners' and operators' resistance to wide single tires. If one tire goes out with dual tires, the trucker can drive to the next truck stop for repairs. With a wide single tire, the trucker would be stuck on the side of the road.

It was suggested that the DOE Aero Team act as a clearing house by testing conceptual designs that appear promising and put out the information. Informing the fleet owners and operators of the benefits of aero devices for reducing fuel use is considered a method for encouraging the use of advanced technology. Suggested was the participation of the DOE Aero Team in American Trucking Association (ATA) or Truck Maintenance Association (TMA) meetings.

Collaborative efforts with tractor and trailer OEMs and fleet owners and operators were encouraged. Industry encourages DOE to fund CRADA activities. The attending tractor OEMs mentioned that they have submitted proposals to DOE which have been accepted, but the promised funding has not arrived. DOE participants reminded all that for an activity to be considered as a DOE CRADA, there should be shared information so that the data is put out there for Nation-wide impact. It is also important to note that DOE can not be a "certifying agency".

The DOE Aero Team needs inexpensive means of testing devices. Fred presented results of his experiments at Crow's Landing in California with the trailer base flaps. Demonstrated was a 4\% fuel savings at an optimum base flap angle of 13 degrees. The cost of a base flap is $\$ 500$ with a savings of $\$ 2,000$ per year per truck. Fred mentioned that the device may also make possible a three fold drag increase by flipping the flaps outward, thus providing braking assistance.

The condition of the Crow's Landing track and weather conditions at the sight were discussed. One participant suggested that an anemometer be used with future experiments at Crow's Landing to provide instantaneous wind yaw. David Whitfield suggested that the Team consider the TVA test track in Chattanooga. He offered to investigate this option. Chris Roy suggested the test track at Auburn University, but its limited speed of 45 miles per hour was considered not acceptable by participants. 


\section{Path Forward}

Attached are the viewgraphs presented by Rose McCallen, providing a brief summary of the program's "Path Forward". Basil Hassan facilitated the discussion that followed the presentation. David Pointer and David Whitfield constructed a summary of the discussion. The summary viewgraphs presented by David Pointer are included at the end of this document.

Rose suggested a plan that addresses the issues discussed in the previous session. It was proposed that the DOE Aero Team continue with their computational effort while enhancing their full-scale testing effort in collaboration with fleet owners and manufacturers. Substantial efforts to establish contacts with the fleets are planned. For example, the Team representative, Jim Ross, has been invited to participate in a panel at the TMA meeting in Nashville Tennessee this September. The focus topic of the panel is the recognized increase in fuel use during the cold weather season. Jim will use this opportunity to share the Team's findings with fleet owners and operators and seek their feedback on ways to get aero device technology on the road.

To successfully get aerodynamic devices on the road, it is recommended that full-scale testing be accomplished in collaboration with fleet owners and operators. Testing locations that have been thus far utilized by the Team are the TRC in Ohio and Crow's Landing in California. The TRC recommends SAE testing, but it is too costly at $\$ 25,000$ for the first test configuration and $\$ 5,000$ per added test configuration. The next preference is coast-down tests at $\$ 5,000$ per test configuration. It was noted that the TRC operators do not trust broadcast fuel rates. The tractor manufacturers participating in the meeting prefer coast-down tests and believe that utilizing broadcast fuel rates is acceptable for scoping. The preferred approach is long road testing to capture wind effects. Most meeting participants felt that both controlled and long road tests were needed at speeds at or exceeding 65 miles per hour.

Computations of rotating wheels and investigating the influence of underbody flow are planned and are recognized areas of interest to industry. This effort is in addition to moving forward on full-vehicle simulations with advanced models. Unsteady RANS and hybrid LES/RANS modeling of the full GCM vehicle with comparison and analysis of the 12-ft NASA Pressure Wind Tunnel data is planned. It is important to determine if unsteady RANS and hybrid RANS/LES turbulence modeling can capture primary flow features. Guidelines for steady RANS have been openly shared and are available to industry. Unsteady RANS and hybrid models need to be assessed for grid sensitivity and boundary conditions. This will provide specific guidelines for computations with advanced models and will assist in the further conceptual design of drag reduction devices and an integrated vehicle.

The tractor manufacturers present at the meeting were also interested in computational results for specific commercial tools. It was noted that guidelines for use of specific turbulence modeling approaches is not dependent on choice of computational tool. The request to compare specific commercial tools also poses a difficult situation for the Team members from the National Labs who can not endorse a particular commercial tool. Currently, the National Lab participants are utilizing commercial and NASA codes, as well as their own in-house tools. There are advantages 
to each. For the addition of new models and for response to R\&D issues especially on large parallel machines for investigating model performance, the NASA and in-house tools provide the quickest and most flexible situation. However, for geometry and mesh generation, the commercial tools tend to provide some desirable options.

The specific computations being performed by each organization and the coordination of work for maximum benefit were discussed. It was evident that issues of geometry, boundary conditions, and turbulence model characteristics needed further discussion. Planned are a series of conference calls to discuss the following identified topics:

- Appropriateness of truncating the GTS geometry for turbulence model evaluation,

- Dependence of results on upstream tunnel entrance length/vorticity, inclusion of wind tunnel boundaries as limits of computational domain, and grid refinement,

- Appropriate metrics, and

- Choice of benchmark cases for comparison between organizations.

It was recognized that further fuel savings are possible and vehicle safety can be enhanced by leveraging the accomplishments of the DOE Aero Team to investigate an integrated heavy vehicle system. The effect of aerodynamics on brake cooling and engine cooling will be considered. Air control for improved braking and engine performance is currently a high priority for industry. Also, the initiated efforts in wheel, tire, and vehicle splash and spray will continue. This splash and spray investigation will provide an understanding of this multiphase flow phenomena, thus leading to conceptual designs for mitigation of splash and spray for improved vehicle and highway safety. Published research and development in the open literature appears to be void of information in this area of interest.

The Team is also planning to continue their pursuit to improve aerodynamics and reduce fuel use areas with similar flow regimes to that of heavy vehicles. This year's experiments and computations of railway coal cars have demonstrated the substantial increase in drag from full to empty railcars. The aerodynamic drag of an empty railcar in the wind tunnel is $32 \%$ and $42 \%$ at 0 and 10 degrees yaw, respectively, over that for a full railcar. We plan to continue working with contact, Jim Hart, of Johnstown America Corporation, Johnstown, Pennsylvania for guidance in conceptual designs that are automatic and durable for the 20 plus year life of a coal car.

Experiments and computations will be used for the smart design of drag mitigating devices. These conceptual designs will condition the flow so that the empty car will mimic the flow of a full car, providing substantial fuel savings. 


\section{Truck Aero Team Meeting Attendees}

Doubletree Jantzen Beach, Portland, Oregon

July 1, 2004

\begin{tabular}{lll} 
Attendee & Organization & e-mail address and phone \\
Diego Arcas & USC & arcasrod@usc.edu \\
Bruno Banceu & Freightliner & BrunoBanceu@Freightliner.com, 503-745-7882 \\
Fred Browand & USC & browand@spock.usc.edu, 213-740-5359 \\
Chad Brown & Auburn Univ. & \\
Paul Castellucci & LLNL & castellucci1@1lnl.gov, 925-423-0348 \\
Larry Dechant & SNL & ljdecha@mailgate.sandia.gov, (505)844-4250 \\
Sid Diamond & DOE & sid.diamond@ee.doe.gov, 202-586-8032 \\
Craig Eastwood & LLNL & eastwood2@llnl.gov, 925-423-4899 \\
Robert Funk & GTRI & robert.funk@gtri.gatech.edu \\
Paul Hancock & PACCAR & Paul.Hancock@PACCAR.com, (360) 757-5462 \\
Basil Hassan & SNL & bhassan@sandia.gov, 505-844-4682 \\
Sunil Jain & Navistar-Int. & Sunil.Jain@nav-international.com, 260-428-3783 \\
Tony Leonard & Caltech & tony@galcit.caltech.edu, 626-395-4465 \\
Helen Magann & LLNL & magann2@1lnl.gov, 925-422-5229 \\
Matt Markstaller & Freightliner & MattMarkstaller@freightliner.com, 503-745-6857 \\
Rose McCallen & LLNL & mccallen1@1lnl.gov, 925-423-0958 \\
Jason Ortega & LLNL & ortega17@1lnl.gov, 925-423-3824 \\
David Pointer & ANL & dpointer@anl.gov, 630-252-1052 \\
Jim Ross & NASA ARC & jcross@mail.arc.nasa.gov, 650-604-6722 \\
Jules Routbort & ANL/DOE & routbort@anl.gov, 630-252-5065 \\
Chris Roy & Auburn Univ. & cjroy@eng.auburn.edu, 334-844-5187 \\
Kambiz Salari & LLNL & salari1@1lnl.gov, 925-424-4635 \\
Dan Schlesinger & Freightliner & DanSchlesinger@Freightliner.com, 503-745-6975 \\
Donald Smith & Freightliner & DonaldSmith@Freightliner.com, 503-745-7882 \\
Tanju Sofu & ANL & TSofu@anl.gov, 630-252-9673 \\
Bruce Storms & NASA ARC & bstorms@mail.arc.nasa.gov, 650-604-1356 \\
Lee Talmack & Aeroworks & \\
David Whitfield & UTC & Dave-Whitfield@utc.edu \\
Karla Younessi & Freightliner & KarlaYounessi@Freightliner.com \\
\hline & &
\end{tabular}


AGENDA

\section{Heavy Vehicle Aerodynamic Drag: Working Group Meeting \\ Doubletree Jantzen Beach, Multnomah Room \\ Portland, OR}

\section{Purpose of Meeting}

\section{July 1, 2004}

1. Provide summary of achievements, discuss pressing issues, and present general overview of plans

2. Dialogue with industry

\section{Introduction}

$\begin{array}{lll}12: 00-12: 45 \mathrm{PM} & \text { Lunch } & \\ 12: 45-1: 00 \mathrm{PM} & \text { Welcome and introduction } & \text { Rose McCallen (LLNL) } \\ 1: 00-1: 30 \mathrm{PM} & \text { Words of wisdom Sid Diamond (DOE), Jules Routbort (DOE/ANL) }\end{array}$

Achievements

\begin{tabular}{|c|c|c|}
\hline $1: 30-1: 45 \mathrm{PM}$ & Exp. \& comp. directed drag reduction devices & Jim Ross (NASA) \\
\hline $1: 45-2: 00 \mathrm{PM}$ & Discussion & \\
\hline $2: 00-2: 15 \mathrm{PM}$ & Break & \\
\hline
\end{tabular}

Main Issues

$\begin{array}{lll}2: 15-2: 30 \mathrm{PM} & \text { Presentation of issues } & \text { Kambiz Salari (LLNL) } \\ 2: 30-3: 30 \mathrm{PM} & \text { Facilitated Discussion - informal } & \text { Fred Browand (USC) } \\ 3: 30-3: 45 \mathrm{PM} & \text { Break } & \\ 3: 45-4: 00 \mathrm{PM} & \text { Summary } & \text { Jason Ortega (LLNL), Robert Funk (GTRI) }\end{array}$

Path Forward
$4: 00-4: 15 \mathrm{PM}$
Overview
Rose McCallen (LLNL)
$4: 15-5: 15 \mathrm{PM}$
Facilitated Discussion - informal
Larry Dechant (SNL)
$5: 15-5: 30 \mathrm{PM}$
Break
$5: 30-5: 45 \mathrm{PM}$
Summary
David Whitfield (UT), David Pointer (ANL)

Perspectives and Conclusions
$6: 00-7: 15 \mathrm{PM}$
Dinner
$6: 00-7: 15 \mathrm{PM}$
Hubbert's Peak - Has oil production peaked? Fred Browand (USC)
$7: 15-8: 00 \mathrm{PM}$
Discussion, wrap-up Sid Diamond (DOE), Rose McCallen (LLNL) 


\section{Heavy Vehicle Drag Reduction Program Management Accomplishments}

- Congratulations to Sid and Jules for keeping the program alive in turbulent times

- Rose too, for keeping everyone working toward the goals 


\section{Heavy Vehicle Drag Reduction Program Accomplishments}

- Excellent progress toward 25\% drag-reduction goal

- Several concepts and devices demonstrated which could meet the $25 \%$ goal ( $12.5 \%$ increase in fuel efficiency)

- Highly successful testing program

- Detailed CFD validation data available and established guidelines for wind-tunnel testing

- Discovery experiments provided better understanding of flow physics and demonstrated new ways to reduce drag

- Two drag-reduction concepts tested "on the road"

- Outstanding computational flow modeling

- Reliable guidance on obtaining good CFD results (gridding, turbulence models, etc.)

- Improved understanding of flow physics

- Successful and ongoing collaborations with Industry 


\section{Decreasing the Aerodynamic Drag of Tractor/Trailers}

- Gap flow control

- Cab side extenders - reduced drag at yaw

- Gap stabilizer - similar effect

- Base-drag reduction

- Offset boat-tail plates (8\% drag reduction - wind tunnel)

- Base flaps (12\% drag reduction in wind tunnel and $\sim 8 \%$ in road tests)

- Coanda blowing (25\% drag reduction in wind tunnel and $~ 5 \%$ increased efficiency in road tests)

- Oscillatory blowing (no change but interesting flow physics)

- Underbody flow control

- Trailer wheel wedge/fairing (2\% drag reduction in wind tunnel)

- Trailer side skirts ( $\sim 6 \%$ drag reduction in wind tunnel)

- Belly box trailer ( $~ 8 \%$ drag reduction in wind tunnel) 


\section{Decreasing the Aerodynamic Drag of Tractor/Trailers}

- Gap flow control

- Cab side extenders - reduced drag at yaw

- Gap stabilizer - similar effect

- Base-drag reduction

- Offset boat-tail plates (8\% drag reduction - wind tunnel)

- Base flaps (12\% drag reduction in wind tunnel and $\sim 8 \%$ in road tests)

- Coanda blowing (25\% drag reduction in wind tunnel and $~ 5 \%$ increased efficiency in road tests)

- Oscillatory blowing (no change but interesting flow physics)

- Underbody flow control

- Trailer wheel wedge/fairing (2\% drag reduction in wind tunnel)

- Trailer side skirts ( $\sim 6 \%$ drag reduction in wind tunnel)

- Belly box trailer ( $~ 8 \%$ drag reduction in wind tunnel)
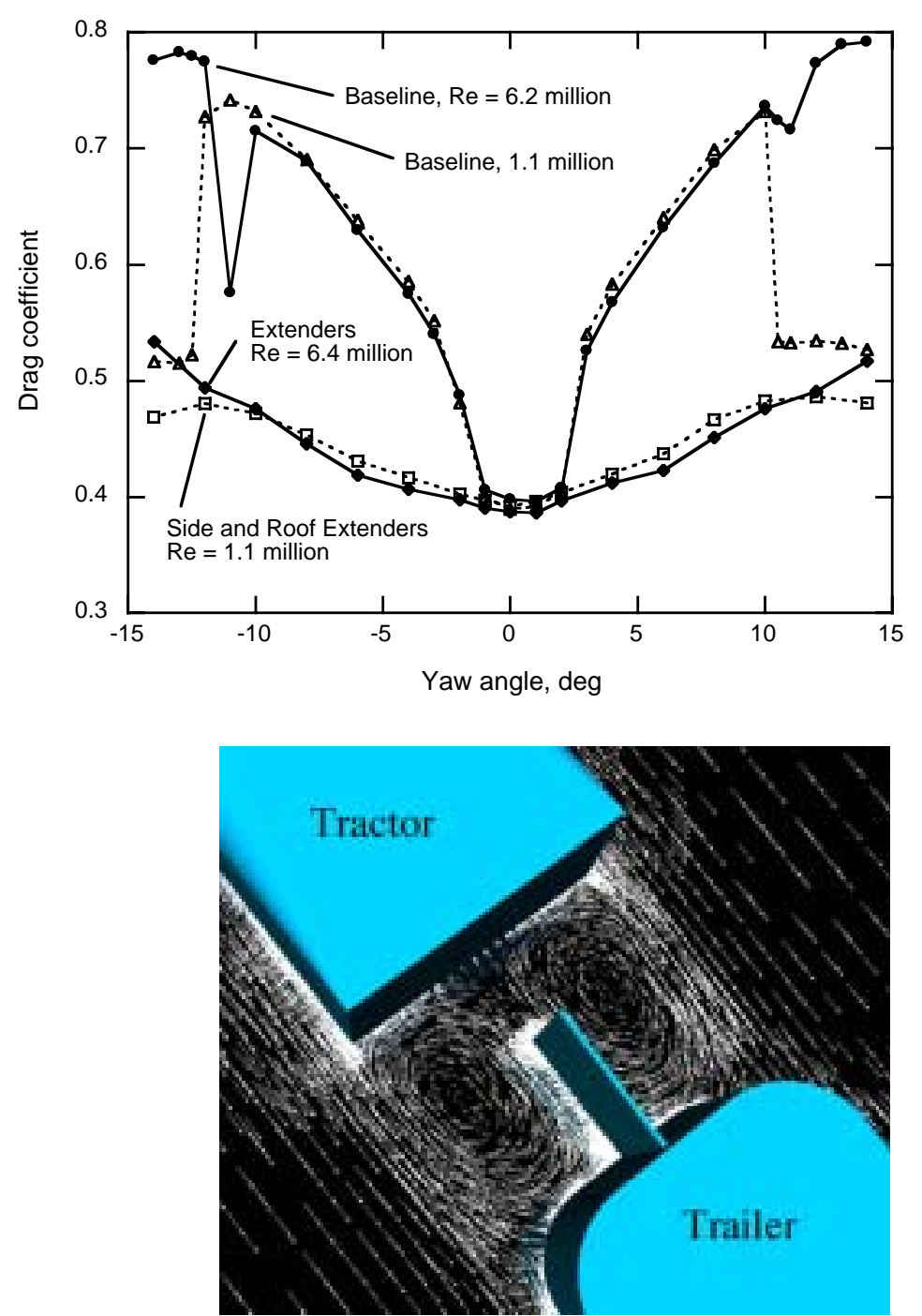


\section{Decreasing the Aerodynamic Drag of}

- Gap flow control

- Base-drag reduction

- Underbody flow co

Tractor/Trailers

- Cab side extenders - reduced drag at yaw

- Gap stabilizer - similar effect

- Offset boat-tail plates (8\% drag reduction - wind tunnel)

- Base flaps (12\% drag reduction in wind tunnel and $\sim 8 \%$ in road tests)

- Coanda blowing (25\% drag reduction in wind tunnel and $~ 5 \%$ increased efficiency in road tests)

- Oscillatory blowing (no change but interesting flow physics)

- Trailer wheel we reduction in win

- Trailer side skirt in wind tunnel)

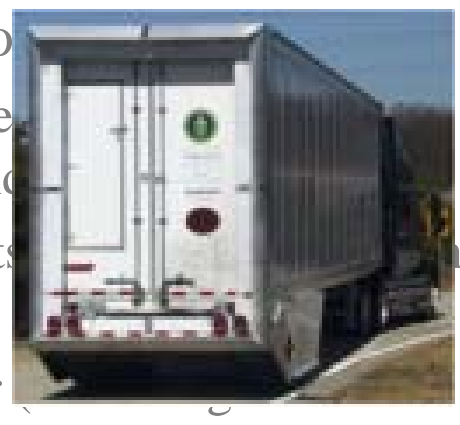

- Belly box trailer
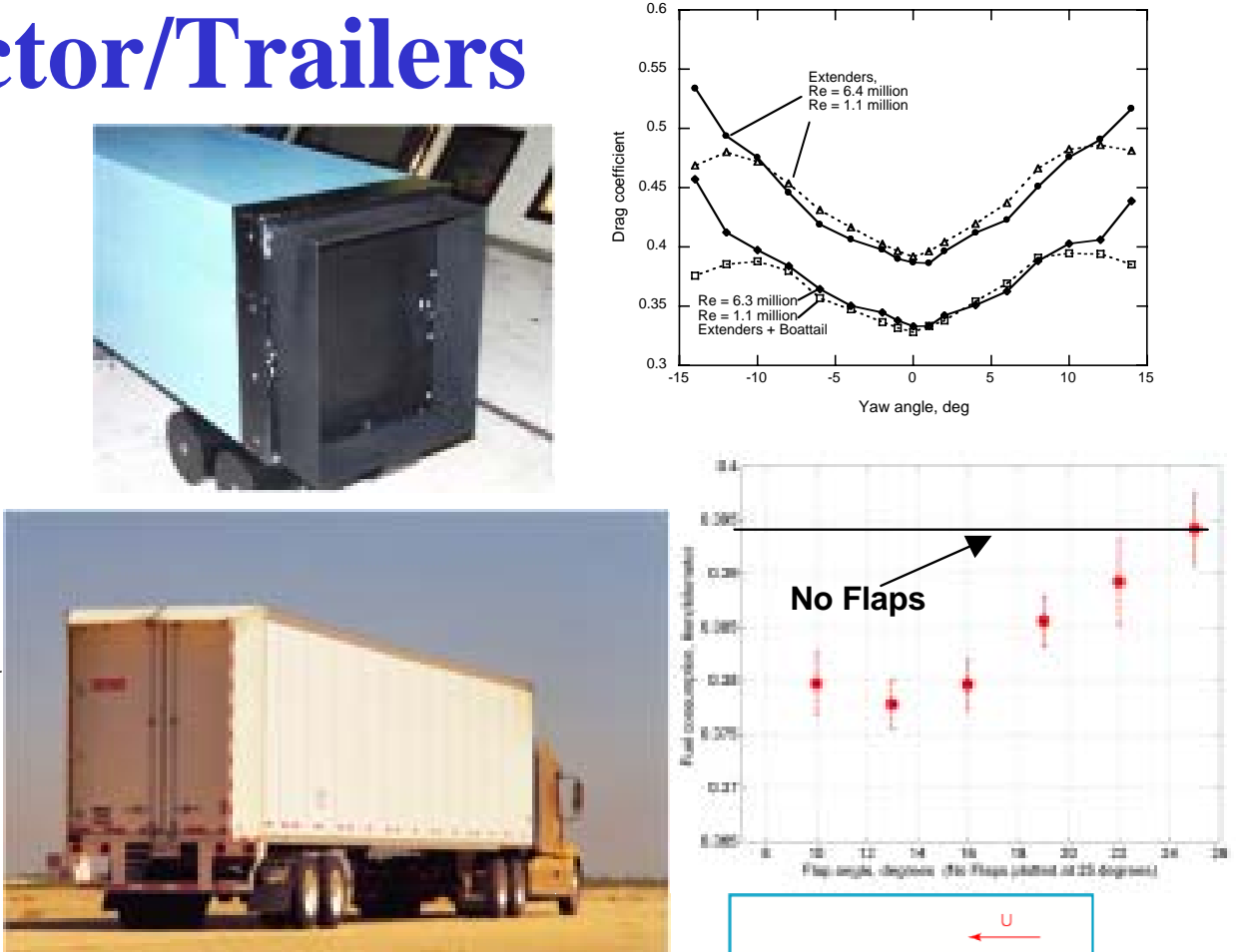
in wind tunnel)
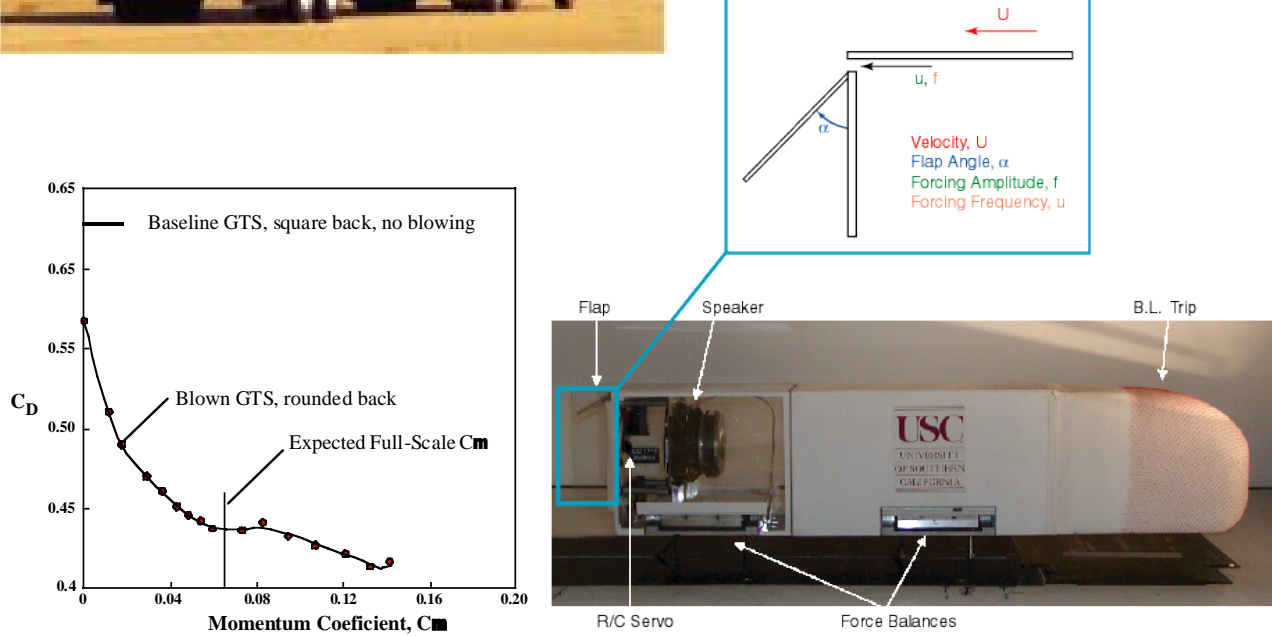


\section{Decreasing the Aerodynamic Drag of Tractor/Trailers}

- Gap flow control

- Cab side extenders - reduced drag at yaw

- Gap stabilizer - similar effect

- Base-drag reduction

- Offset boat-tail plates (8\% drag reduction - wind tunnel)

- Base flaps (12\% drag reduction in wind tunnel and $\sim 8 \%$ in road tests)

- Coanda blowing (25\% drag reduction in wind tunnel and $~ 5 \%$ increased efficiency in road tests)

- Oscillatory blowing (no change but interesting flow physics)

- Underbody flow control

- Trailer wheel wedge/fairing (2\% drag reduction in wind tunnel)

- Trailer side skirts ( $\sim 6 \%$ drag reduction in wind tunnel)

- Belly box trailer ( $\sim 8 \%$ drag reduction in wind tunnel)

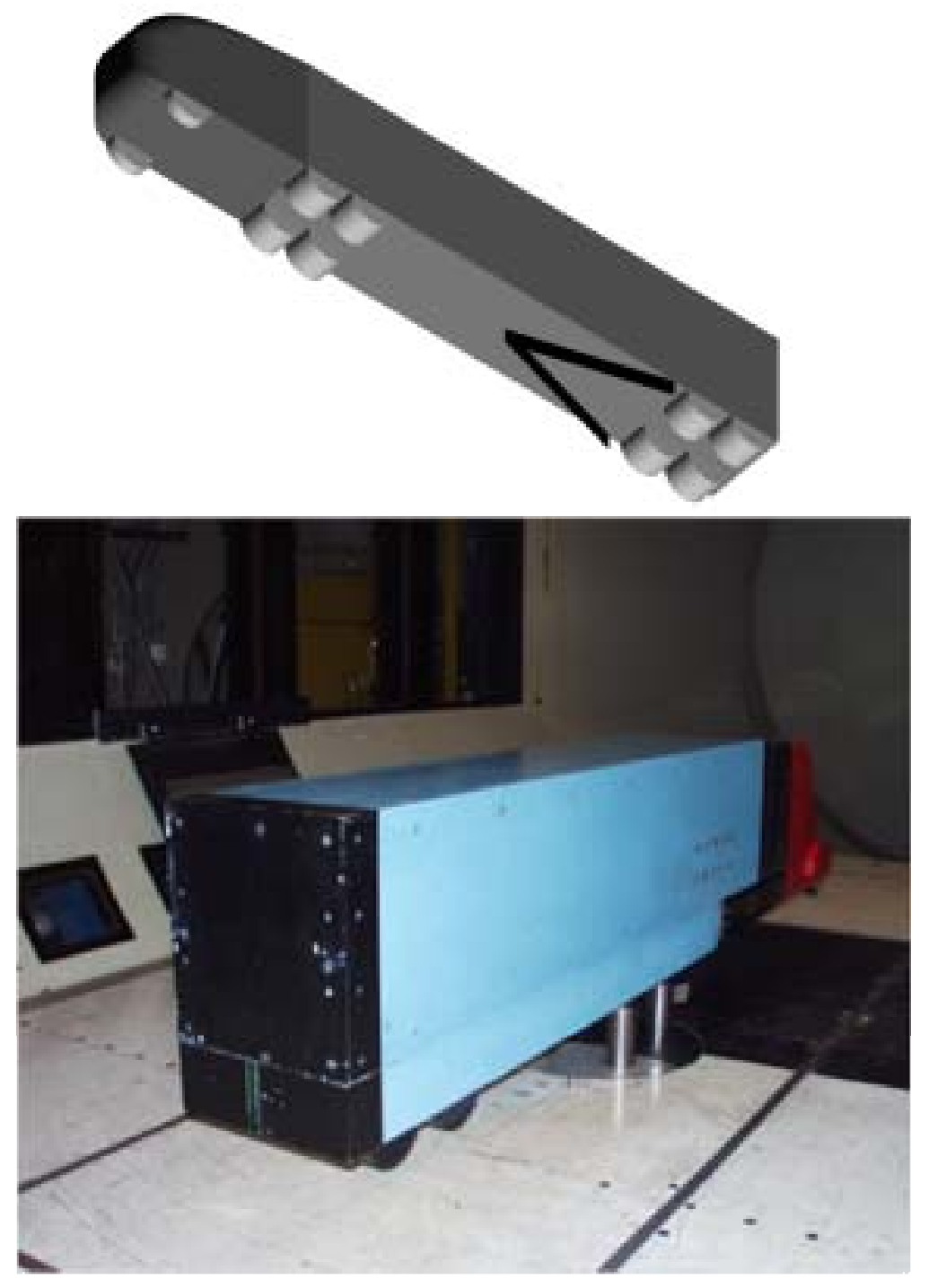




\section{Wide Range of Experimental Projects}

- Detailed CFD Validation Data Available

- GTS model Re $=0.5-2 \mathrm{M}$

- GCM Re $=0.5-6 \mathrm{M}$ (full-scale Re at road speeds in pressurized wind tunnel)

- Pressure distributions, wake and gap region flow-field velocity distributions, unsteady pressure, \& limited skin friction

- Flow Physics Experiments

- Effect of corner radius Re

- Gap flow behavior

- Wake structure

- Test Technique Recommendations

- Critical corner-radius Re

- Scale effects, minimum Re

- Importance of geometric fidelity on basedrag reduction 


\section{Wide Range of Experimental Projects}

- Detailed CFD Validation Data Available

- GTS model Re $=0.5-2 \mathrm{M}$

- GCM Re $=0.5-6 \mathrm{M}$ (full-scale Re at road speeds in pressurized wind tunnel)

- Pressure distributions, wake and gap region flow-field velocity distributions, unsteady pressure, $\&$ limited skin friction

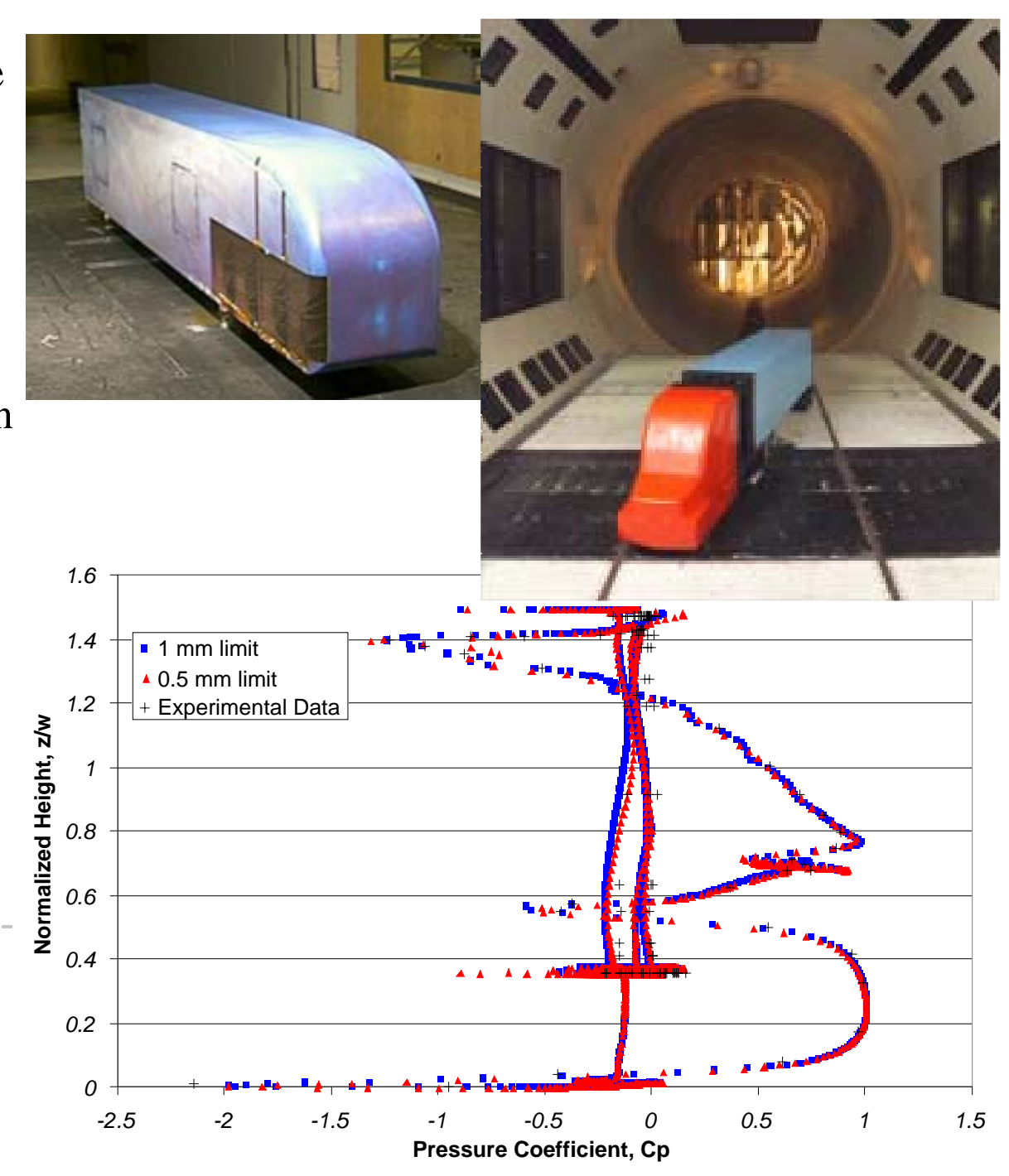

- Flow Physics Experiments

- Effect of corner radius Re

- Gap flow behavior

- Wake structure

- Test Technique Recommendations

- Critical corner-radius Re

- Scale effects, minimum Re

- Importance of geometric fidelity on base drag reduction 


\section{Wide Range of Experimental Projects}

- Detailed CFD Validation Data Available

- GTS model Re $=0.5-2 \mathrm{M}$

- GCM Re = 0.5 - $6 \mathrm{M}$ (full-scale Re at road speeds in pressurized wind tunnel)

- Pressure distributions, wake and gap region flow-field velocity distributions, unsteady pressure, \& limited skin friction

- Flow Physics Experiments

- Effect of corner radius $\mathrm{Re}$

- Gap flow behavior

- Wake structure

- $\quad$ Test Technique Recommendations

- Corner-radius Re $>50,000$

- Minimum model Re > 2-3M for std. config.

- Importance of geometric fidelity on basedrag reduction
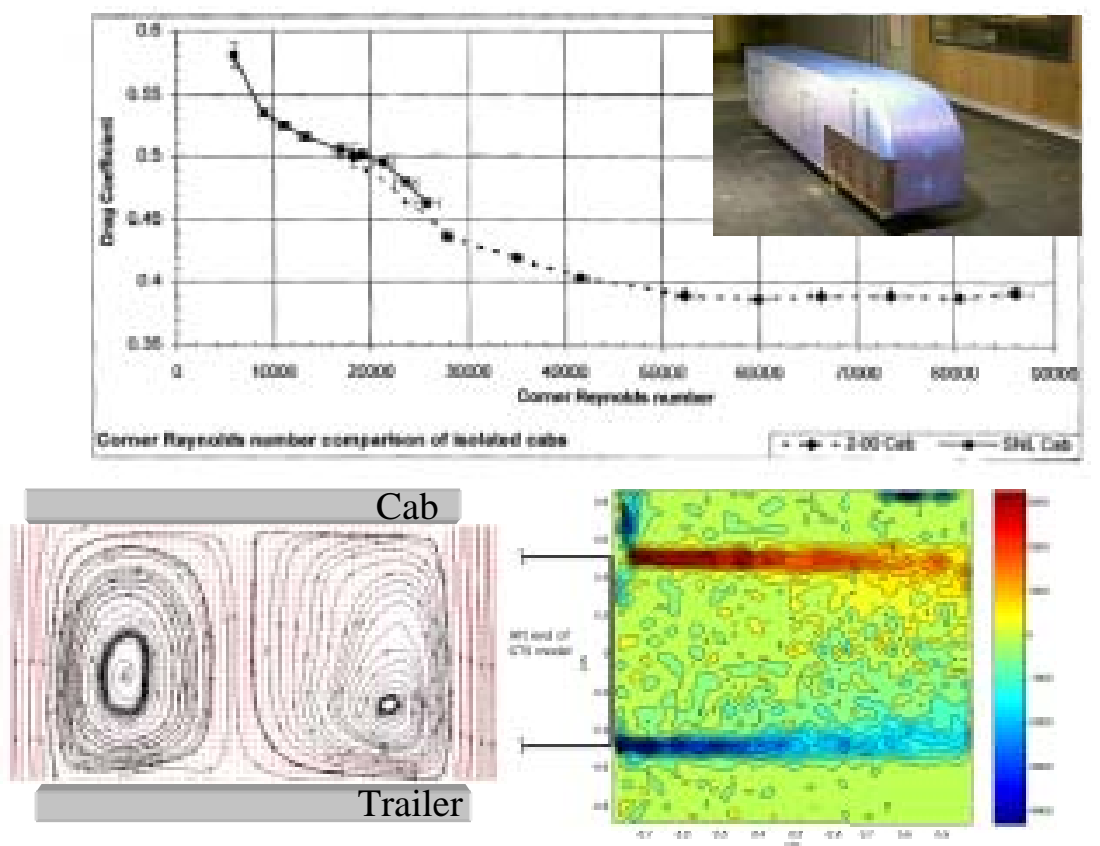

Combined best of academia and government lab capabilities.

Leveraged technical developments across programs within DOE and NASA while delivering program milestones 


\section{Comprehensive Look at Computational Modeling}

- Developed modeling guidelines

- Current generation of RANS codes can accurately predict drag but may still miss flow-field details

- Grid refinement

- Large effect of turbulence model

- Wall functions work if carefully applied

- Variety of methods examined:

- RANS

- URANS

- DES

- Vortex methods

- Computations used for both flow physics and concept evaluation 


\section{Comprehensive Look at Computational Modeling}

- Developed modeling guidelines

- Current generation of RANS codes can accurately predict drag but may still miss flow-field details

- Grid refinement

- Large effect of turbulence model

- Wall functions work if carefully applied

- Variety of methods examined:

- RANS

- URANS

- DES

- Vortex methods
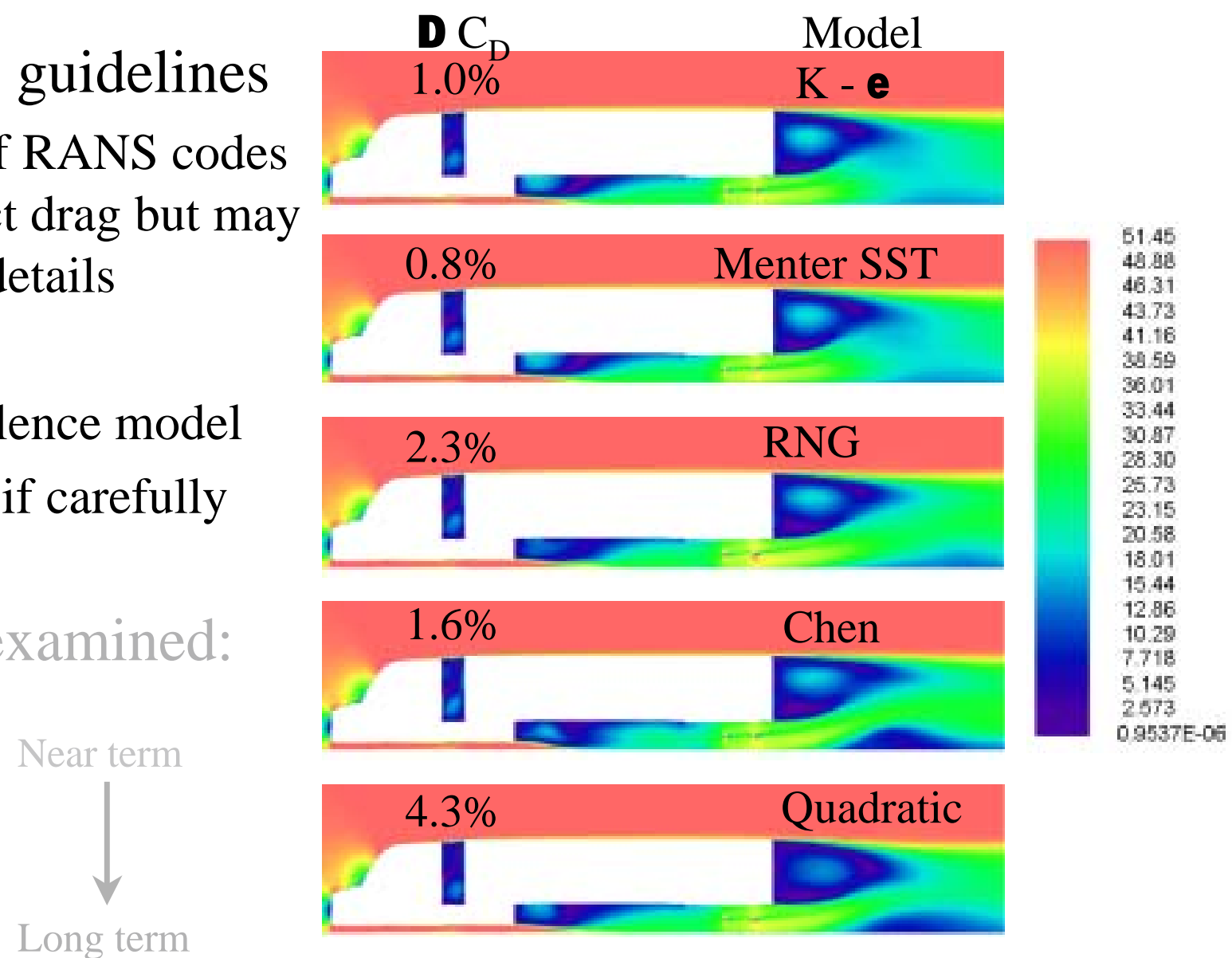

- Computations used for both flow physics and concept evaluation
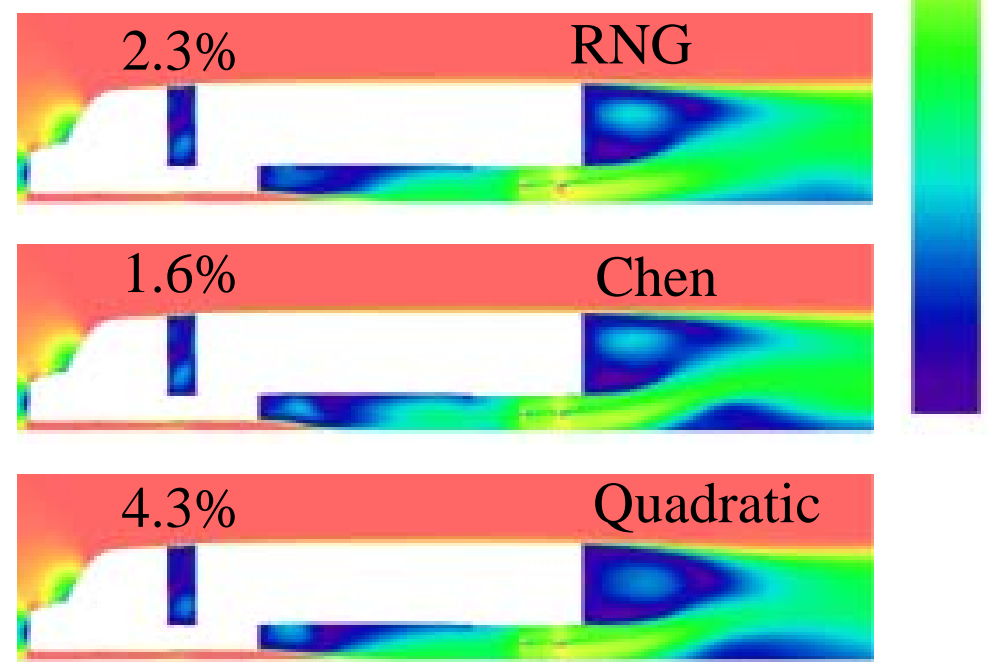

$9537 \mathrm{E}-06$ 


\section{Comprehensive Look at Computational Modeling}

- Developed modeling guidelines

- Current generation of RANS codes can accurately predict drag but may still miss flow-field details

- Grid refinement

- Large effect of turbulence model

- Wall functions work if carefully applied.

- Variety of methods examined:

- RANS

- URANS

- DES

- Vortex methods Long term

- Computations used for both fle physics and concept evaluatio

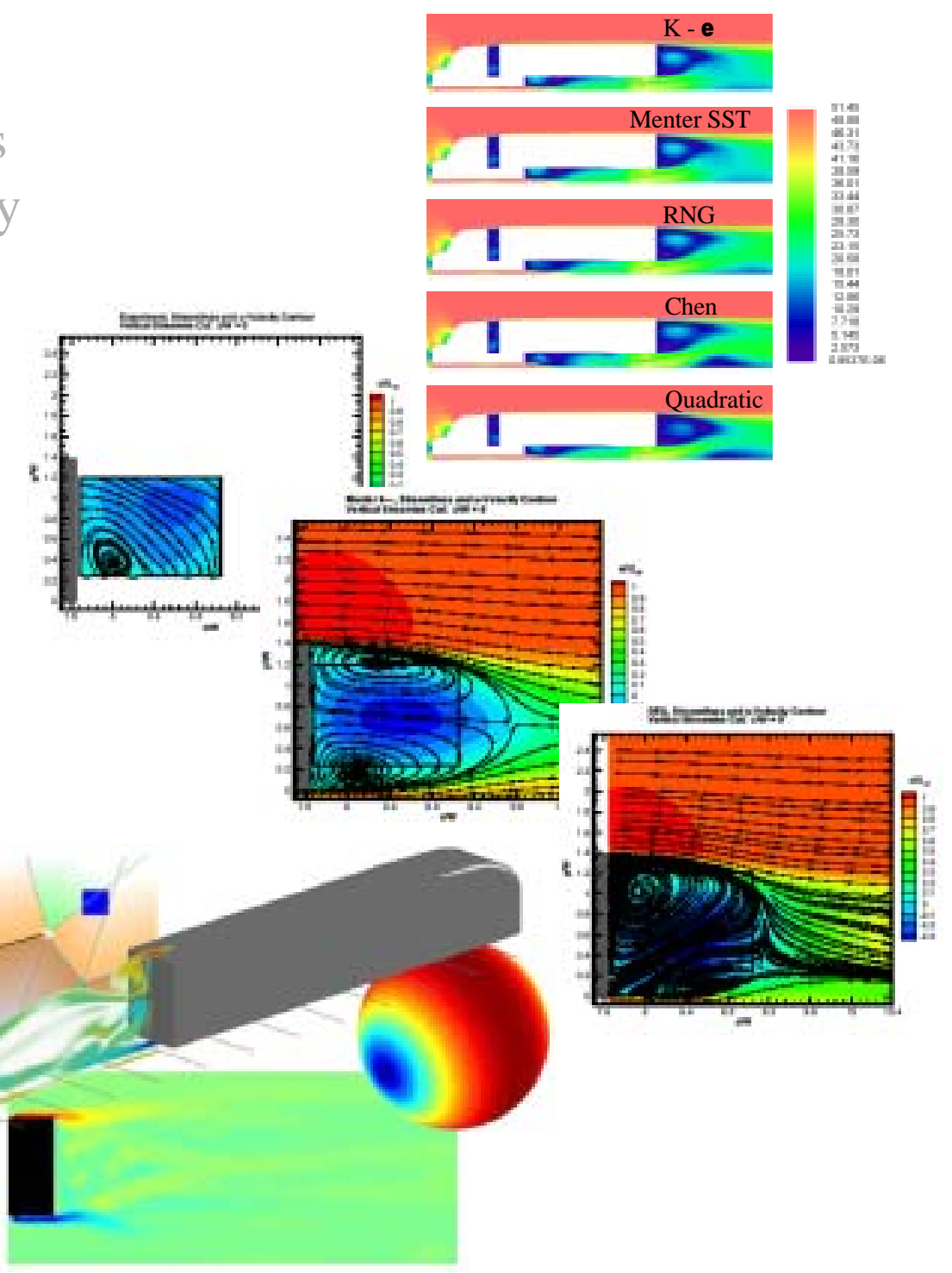




\section{Comprehensive Look at Computational Modeling}

- Developed modeling guidelines

- Current generation of RANS codes can accurately predict drag but may still miss flow-field details

- Grid refinement

- Large effect of turbulence model

- Wall functions work if carefully applied

- Variety of methods examined:

- RANS

- URANS

- DES

- Vortex methods Long term

- Computations used for both flow physics and concept evaluation
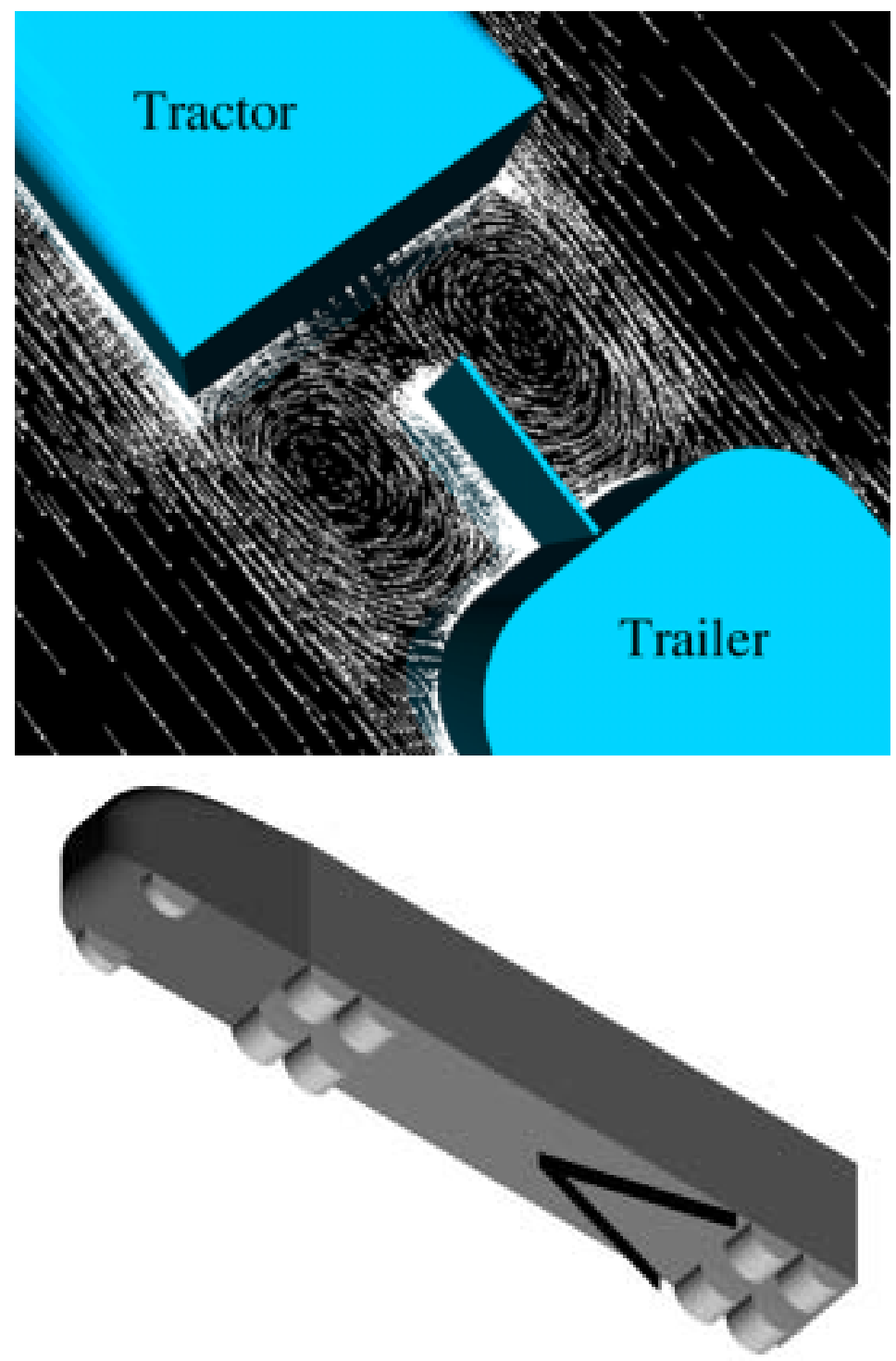


\section{Productive Collaborations Established}

- GTRI/Volvo/Great Dane - Coanda blowing road/track tests

- USC/Michelin - Splash \& spray studies

- USC/Maka Innovations Technologique- Angled boat-tail plates

- ANL/PACCAR - Assessment of CFD capabilities

- NASA/Freightliner - Wind-tunnel design

- Technical papers at SAE \& AIAA conferences

- UEF Conference Dec. 2002 Proceedings to be published in August

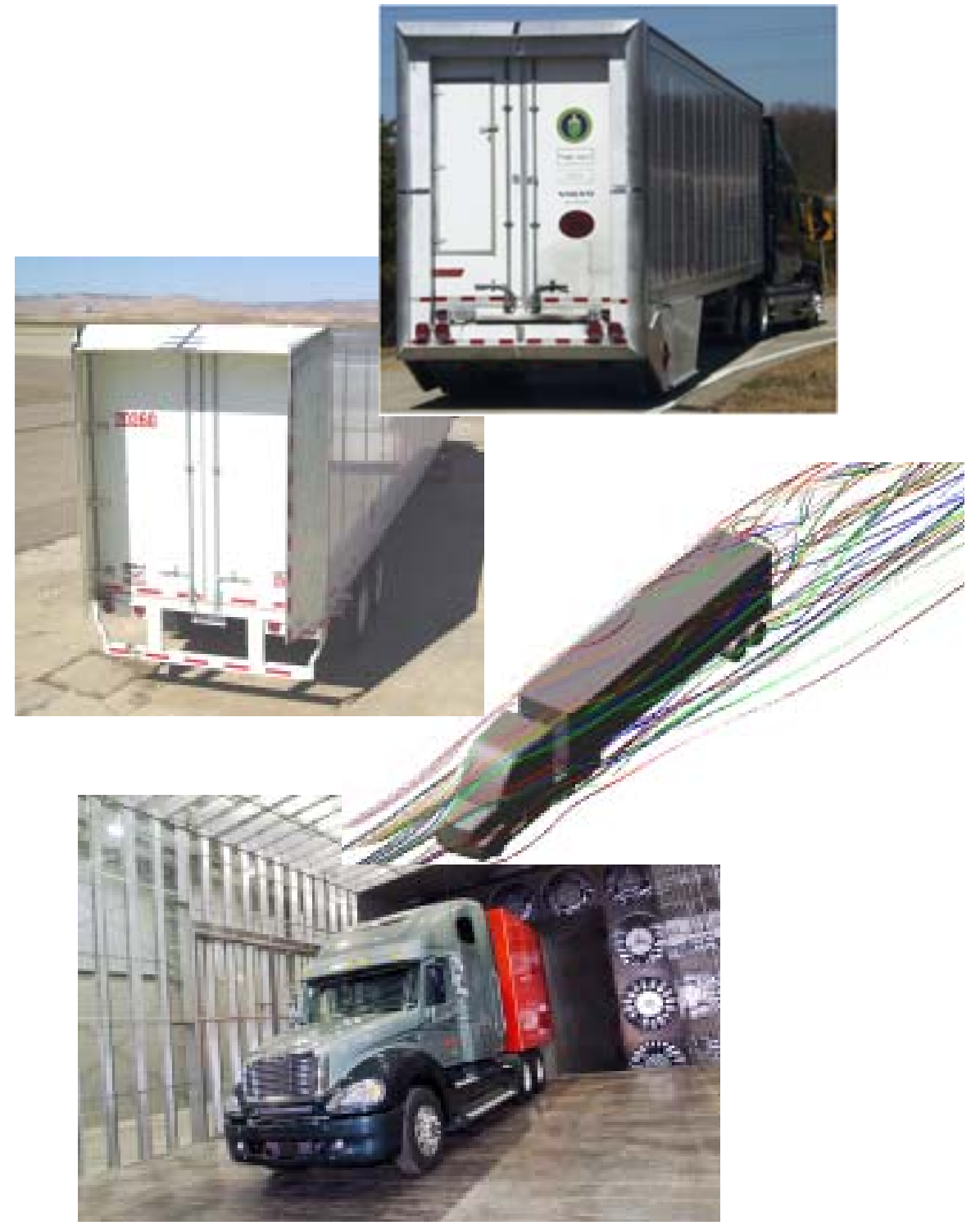




\title{
Move Experimental and Computational Effort Toward Employing Higher Fidelity Models and Realistic Operational Environment
}

\author{
Kambiz Salari
}

Heavy Vehicle Aerodynamic Drag Working Group Meeting

$$
\text { July 1, } 2004
$$




\section{Adequately capture reality for design guidance of heavy vehicles and aero-devices}

- Model scales

- Model fidelity

- Operational environment

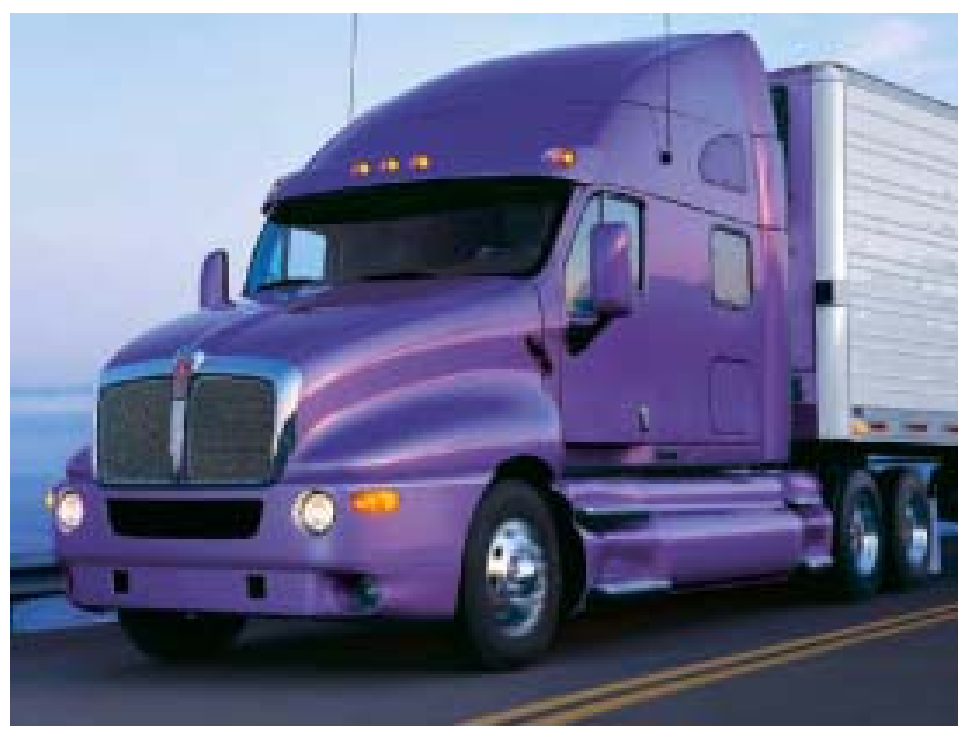




\section{Model fidelity is improving}

- Ground Transportation System (GTS)

- Simplified tractor-trailer geometry

- Extremely useful in validation of computational models

- Generic Conventional Model (GCM)

- More representative of a modern tractortrailer geometry

- Several aero-devices is tested

- To capture realistic performance of drag reducing aero-devices, should we include?

- Wheel wells, wheel rotation, realistic tires

- Flow through engine

- More realistic underbody

- Accessories, such as mirrors, wipers, and grab bars
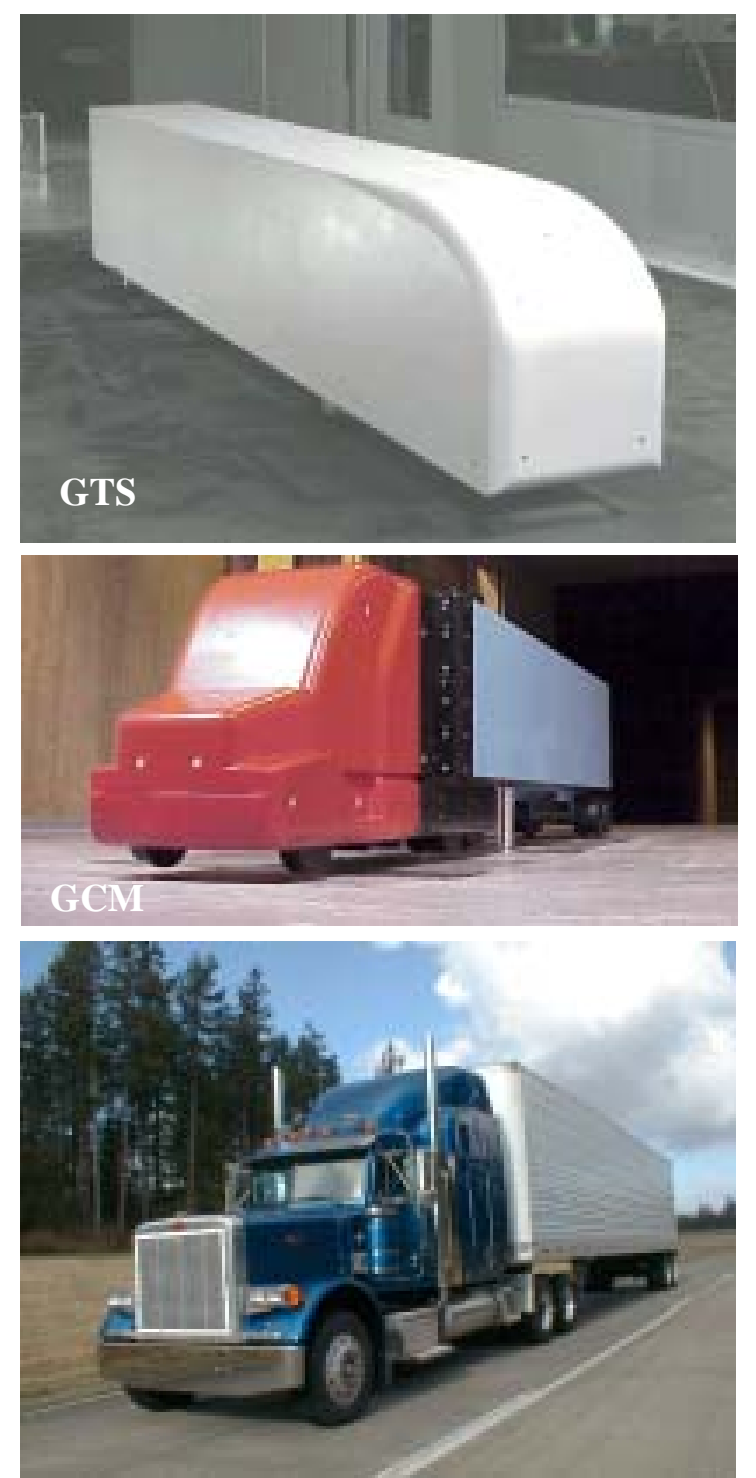


\section{Increase realism of operational environment}

- Modified GTS (1/16 $6^{\text {th }}$ scale) tested in NASA Ames and USC 3'x4' wind tunnel

- Reynolds number attained is about 300,000, based on trailer width

- Higher Reynolds numbers are needed to understand the realistic performance of drag reducing aero-devices

- $\operatorname{GCM}\left(1 / 8^{\text {th }}\right.$ scale $)$ tested in NASA Ames 7'x10' wind tunnel

- Reynolds number attained is about 2 million, based on trailer width

- Several drag reducing aero-devices were tested (no moving ground)

- $\operatorname{GCM}\left(1 / 8^{\text {th }}\right.$ scale) tested in NASA Ames12' pressure wind tunnel

- Full-scale Reynolds number is achieved!

- Several drag reducing aero-devices were tested (no moving ground)

- Full scale test

- Computational modeling and simulation

- Improve predictive capability of simulations with the use of higher fidelity models, flow through engine, and wheel rotation 


\section{Getting drag reducing aero-devices on the road}

- Full-scale testing

- Track testing

- Road testing

- Use by fleet

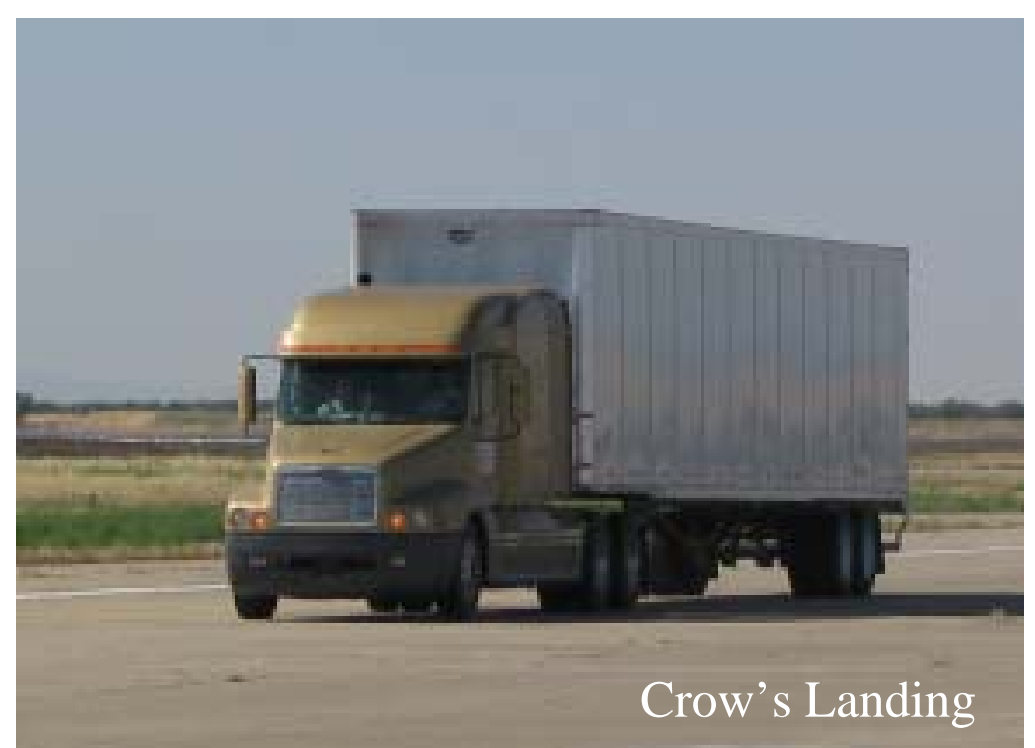

What results are needed to convince OEM's \& fleet-owners? 


\section{Design Guidance for Heavy Vehicles \& Aero-Devices}

Model Fidelity

Operational Environment

--wind tunnel testing

--numerical computation

Implementation of Drag-Reducing Aero-Devices 


\section{Design Guidance for Heavy Vehicles \& Aero-Devices: \\ What is needed to capture reality?}

\section{Model Fidelity:}

The GTS model

Simplified tractor-trailer geometry

Extremely useful in validation of computational models

Generic conventional model

More representative of modern tractor-trailer geometry

A number of aero-devices tested

Should we include?

Wheel wells, wheel rotation, realistic tires, moving ground

Flow through engine

More realistic underbody

Accessories such as mirrors, wipers, grab bars 


\section{Design Guidance for Heavy Vehicles \& Aero-Devices: What is needed to capture reality?}

Operational Environment:

NASA Ames \& USC 3'x4' wind tunnel testing of modified GTS model, $\left(1 / 16^{\text {th }}\right)$

Reynolds number attained $\approx 300,000$, based on trailer width

Useful for elucidating flow physics

Preliminary testing of several aero-device add-ons

NASA Ames 7'x10' testing of GCM (1/8 ${ }^{\text {th }}$ scale)

Reynolds number attained $\approx 2,000,000$

More realistic model geometry

No possibility of moving ground 


\section{Design Guidance for Heavy Vehicles \& Aero-Devices: What is needed to capture reality?}

\section{Operational Environment: (continued)}

NASA Ames 12' pressure wind tunnel

Full-scale Reynolds number achieved!

More realistic GCM geometry

Presently decommissioned?

Computational modeling and simulation

Complement wind tunnel tests

More realistic model geometry, yes but difficult

Moving ground plane, variable inflow conditions are relatively easy to add 


\section{Design Guidance for Heavy Vehicles \& Aero-Devices: Bringing Devices to Market}

What results are needed to convince OEM's, fleet-owners?

Full-Scale Testing

--Track Testing

--Road Testing

How do we (collectively) take the story to the fleet owners? 


\section{Effect of flaps on drag reduction: three experiments}

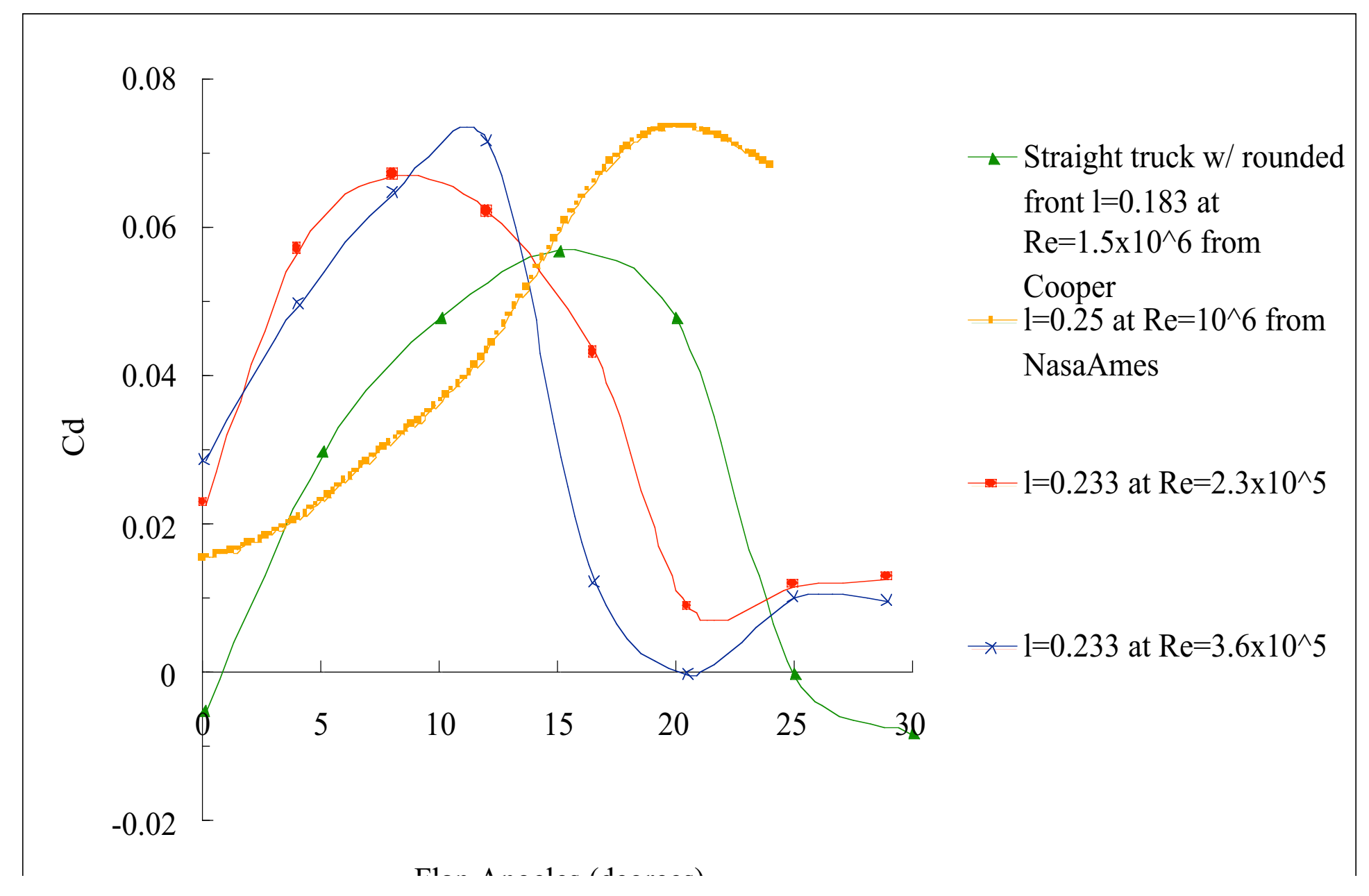




\section{Effect of flaps on drag reduction: four sides forced}

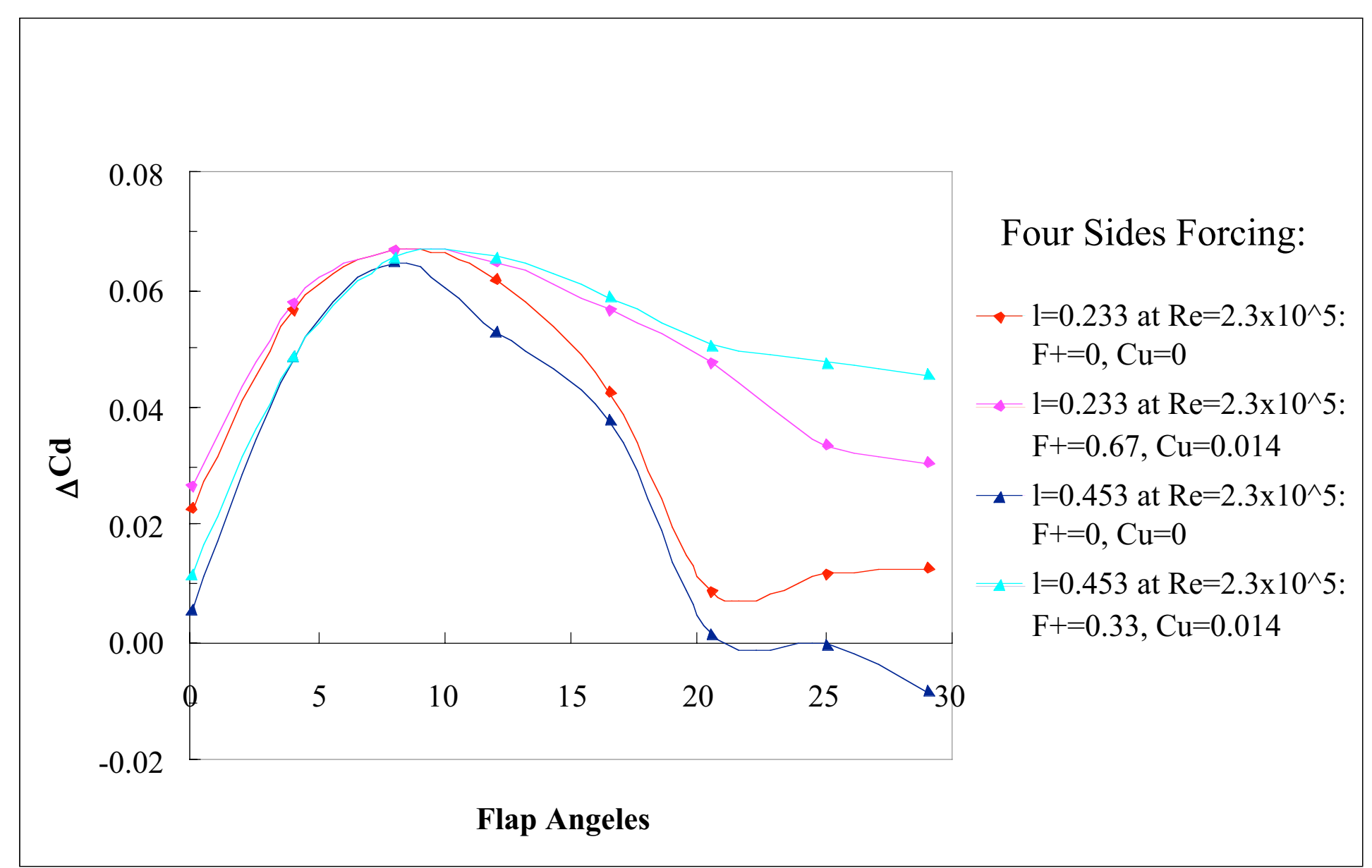




\section{The flaps}
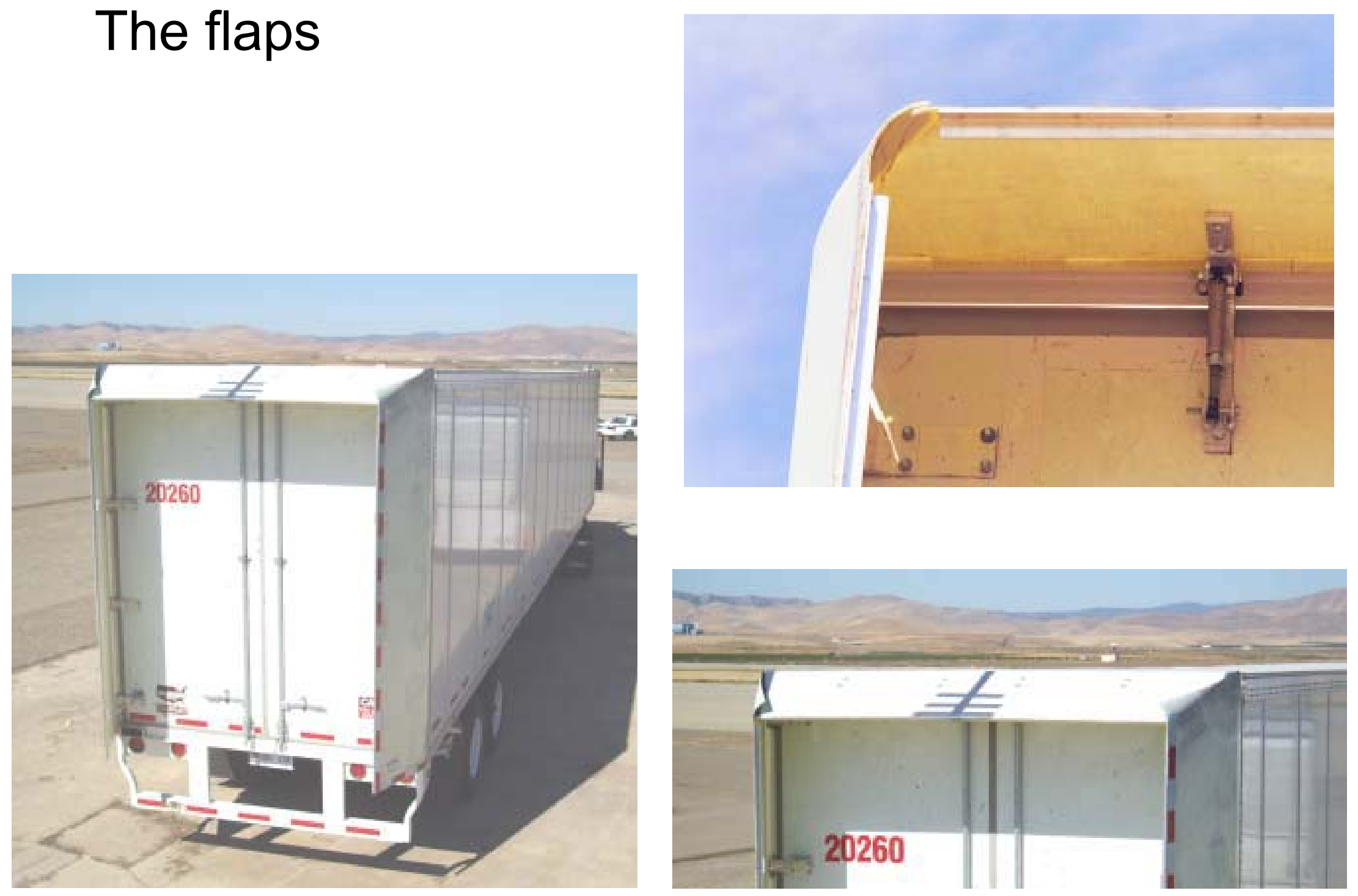


\section{The test procedure}

Record instantaneous fuel consumption (broadcast fuel rate)

Average over central 700 meters of runway traveling in BOTH directions

304 Runs or 152 run-pairs in 5 days

8 Run-pairs $=1$ flap setting $=1$ data set

Collect data set—change flap angle—collect data set—continue

19 Sets of data

Each data set has a mean value, and a standard deviation 


\section{Resulting average fuel consumption}

Previous four methods of data reduction are plotted

They are not so different

All the estimates lay within the established $99 \%$ confidence level estimate

Overall reliability (self consistency) $\approx \pm \ldots$

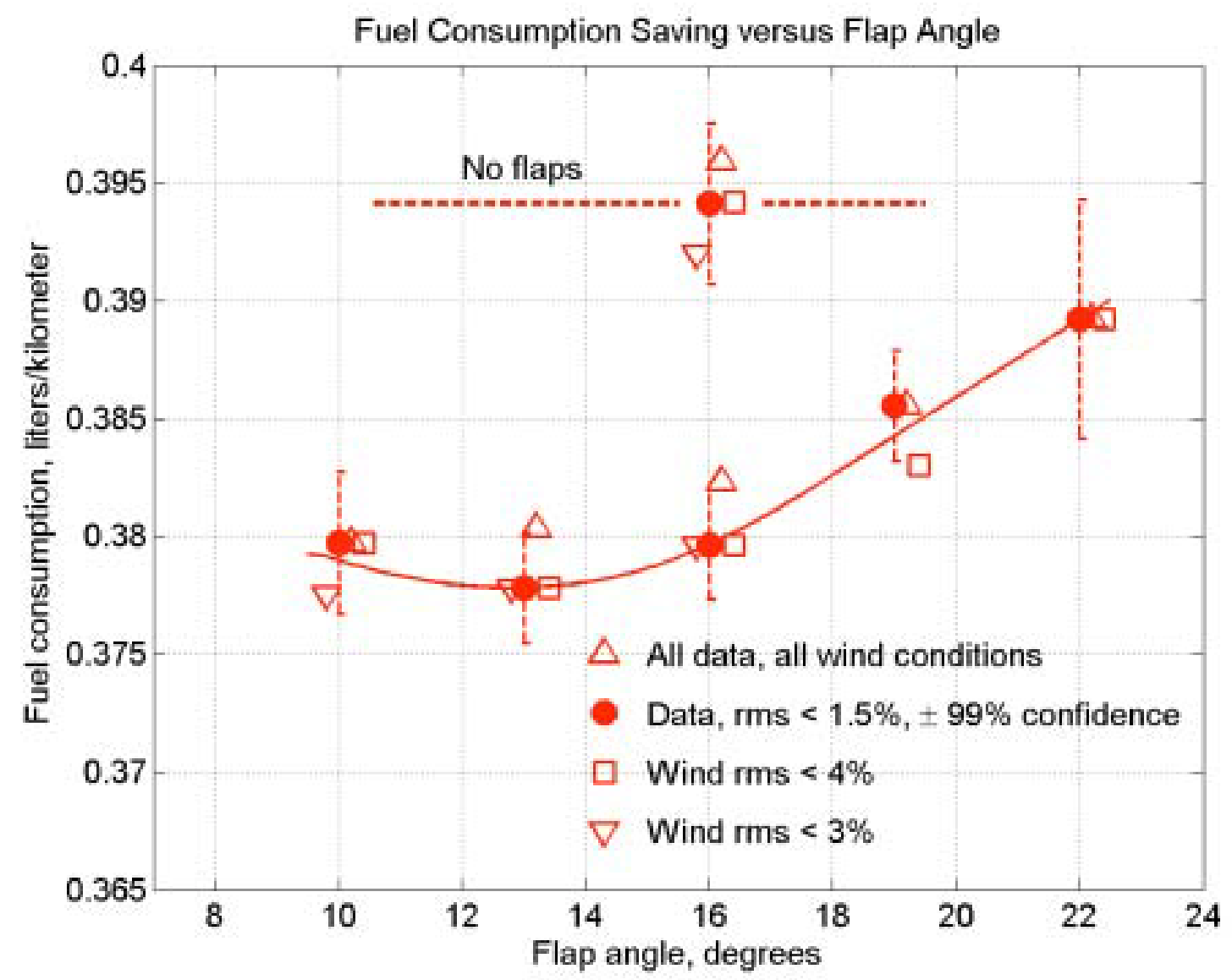

SAE paper No. 05 B-83 


\section{The bottom line}

Based upon:

$\Delta \mathrm{fc}=$ no flaps - flaps@13

$\Delta \mathrm{fc}=1.63$ liters $/ 100 \mathrm{~km}$, or, $\Delta \mathrm{fc}=.693 \mathrm{gal} / 100 \mathrm{miles}$

Fuel price $=\$ 2.20 /$ gal

Savings based upon change in drag produced by adding flaps

Savings will accrue whatever the truck loading condition, and (at least) for moderate wind conditions

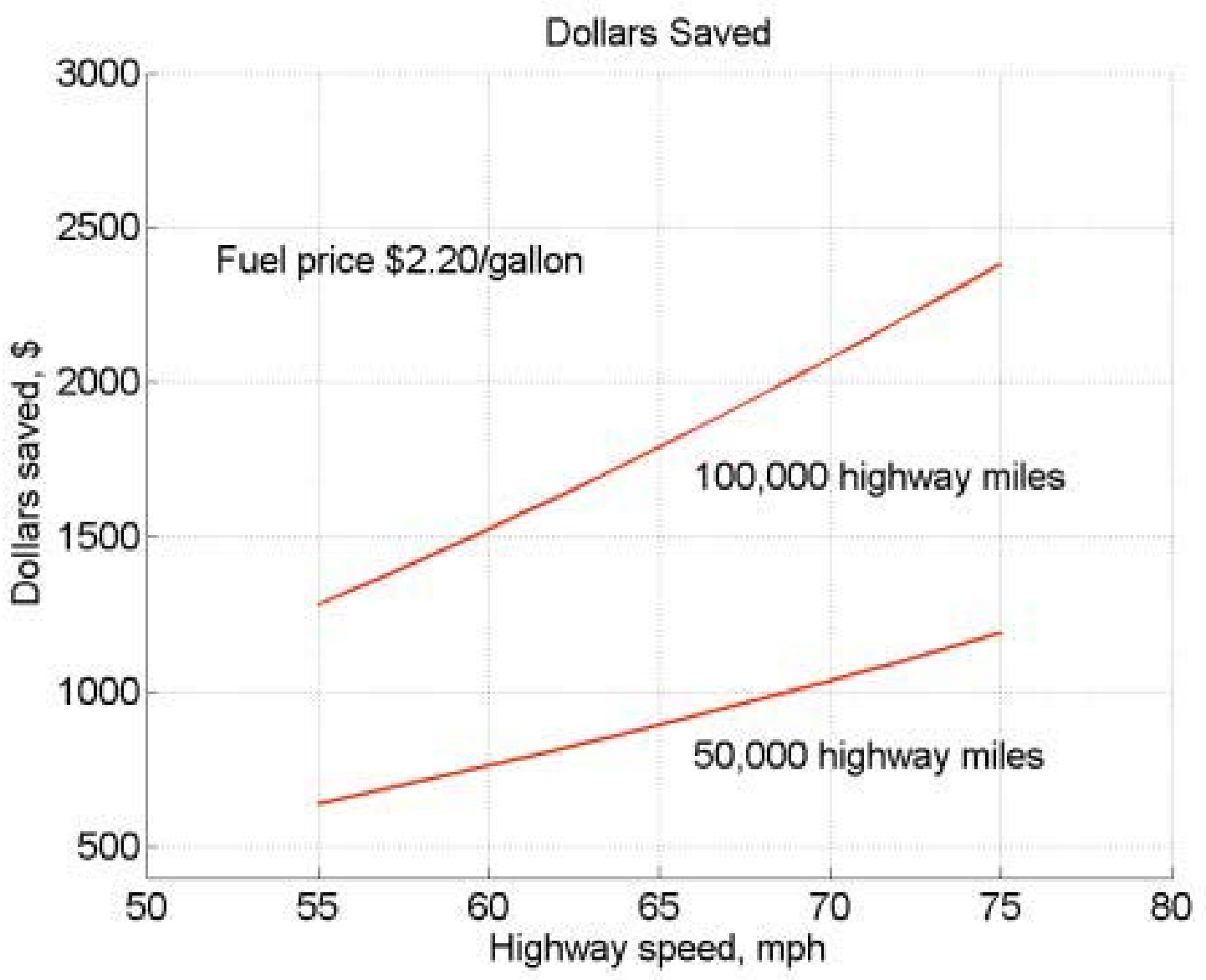

SAE paper No. 05 B-83 


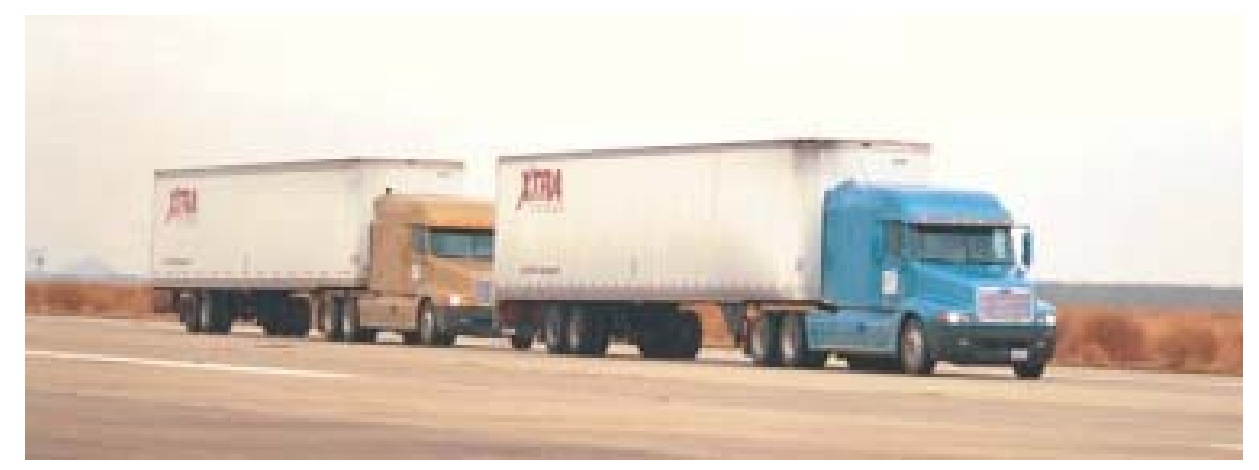

The tandem trucks
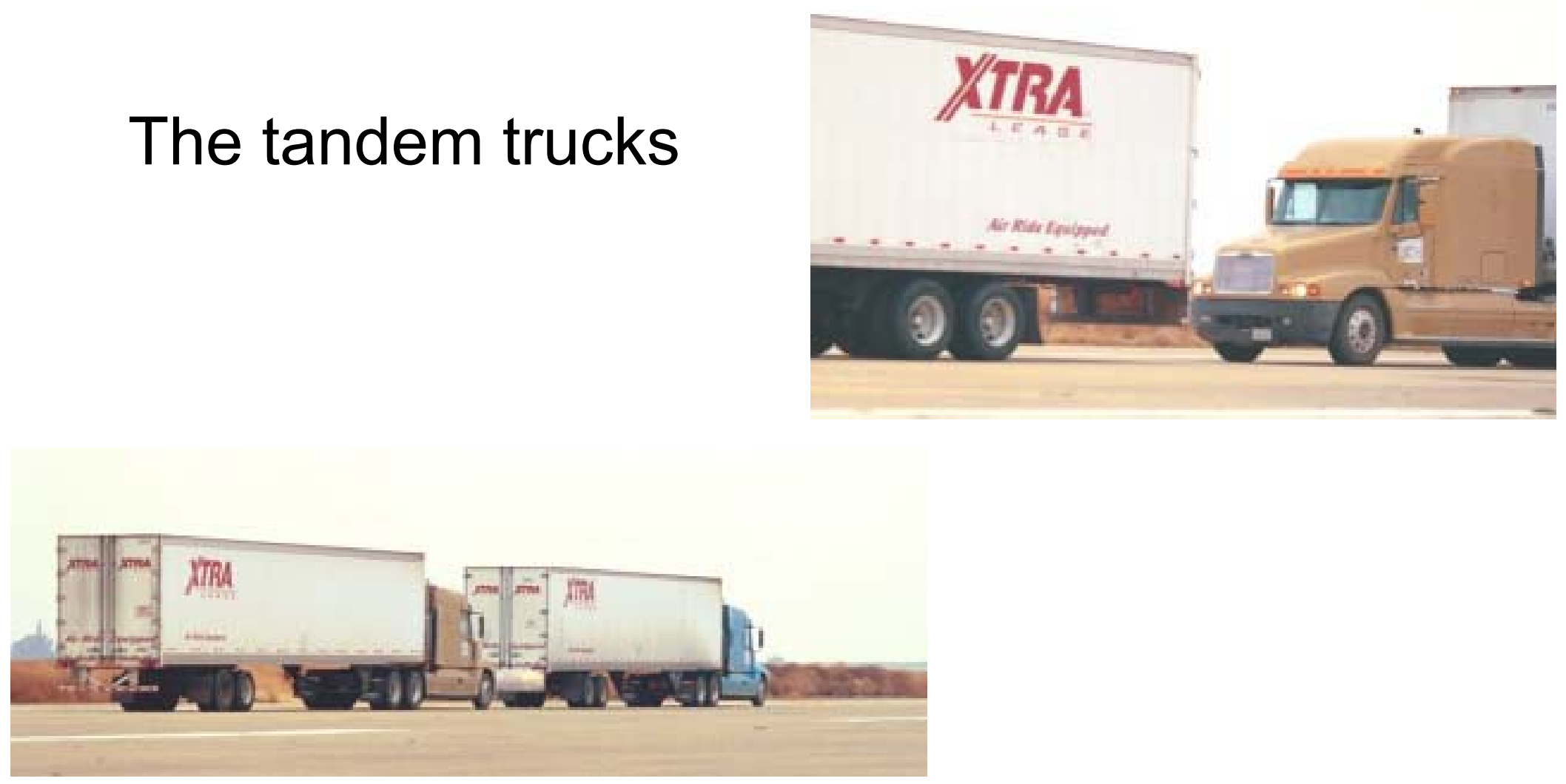


\section{Resulting fuel consumption saving for tandem travel}

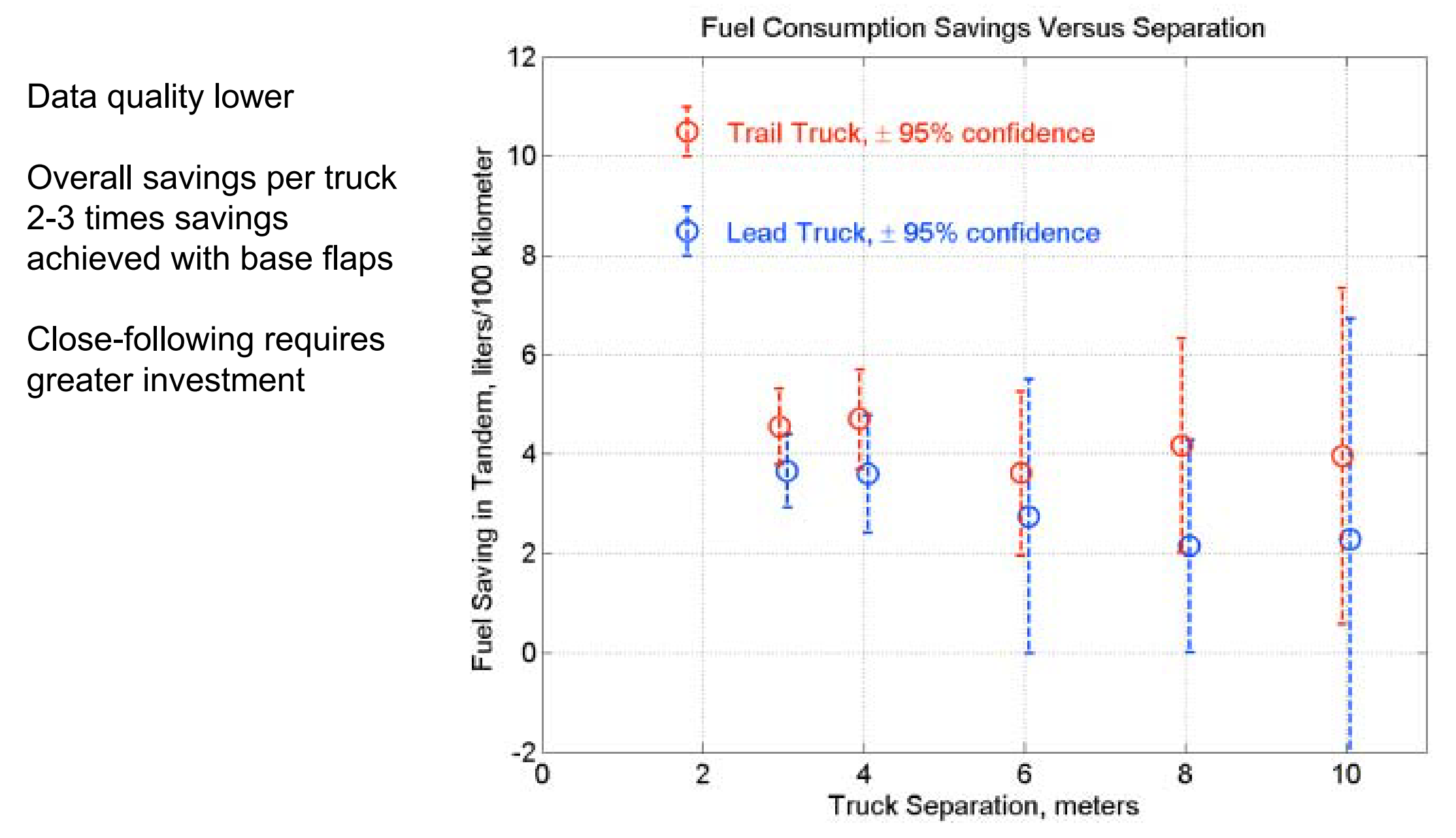

SAE paper No. 05 B-83 


\section{The bottom line, tandem travel, 6-10 meter spacing}

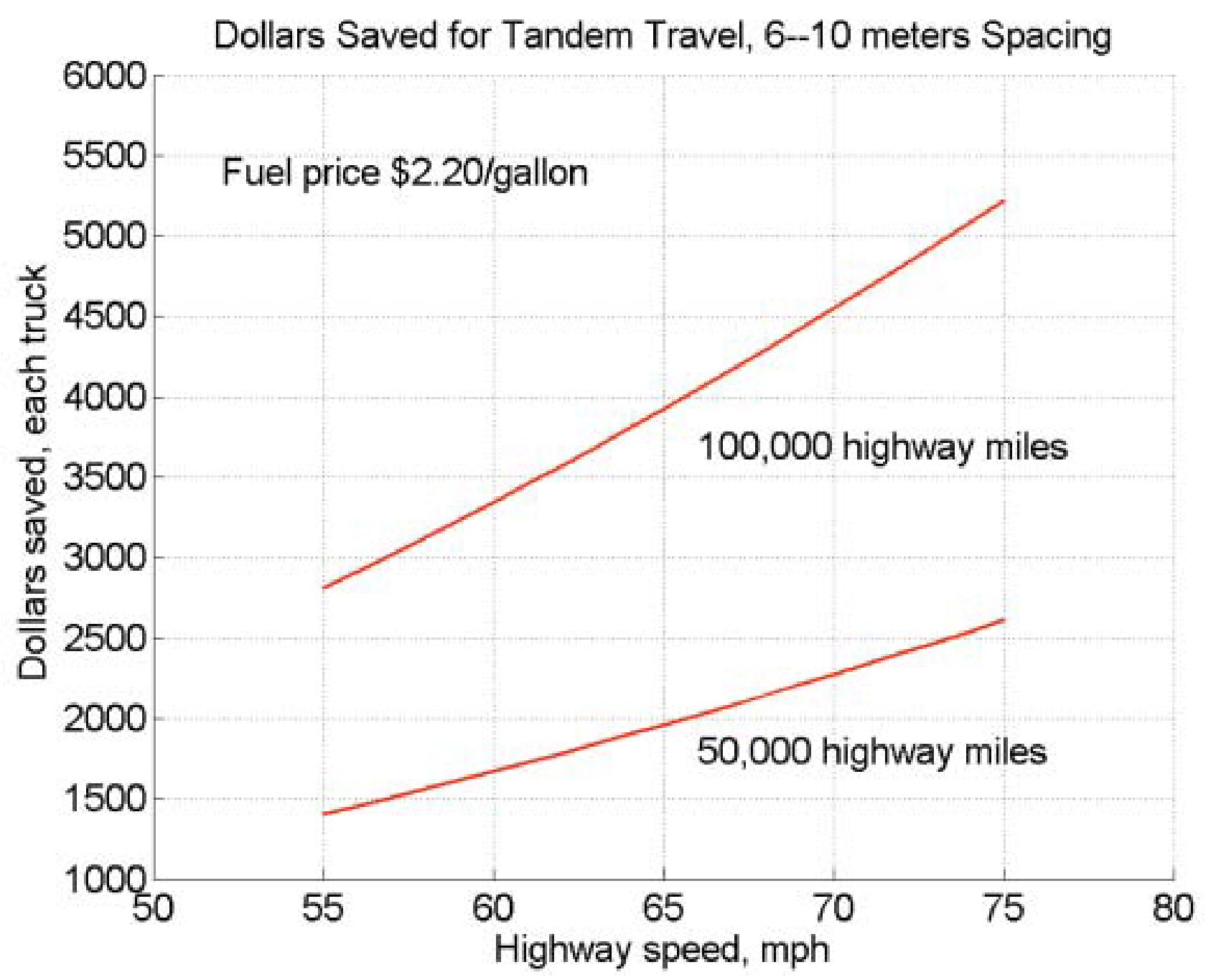

SAE paper No. 05 B-83 
Consortium for Aerodynamic Drag of Heavy Vehicles

Department of Energy, Office of FreedomCAR \& Vehicle Technologies

July 1, 2004

\begin{tabular}{|c|c|}
\hline $\begin{array}{r}\text { Rose McCallen, Kambiz Salari, Jason Ortega, } \\
\text { Craig Eastwood, Paul Castellucci }\end{array}$ & $\begin{array}{l}\text { University of Califormia } \\
\text { 15 Lawrence Livermore } \\
\text { National Laboratory }\end{array}$ \\
\hline Larry DeChant, Chris Roy, Basil Hassan & 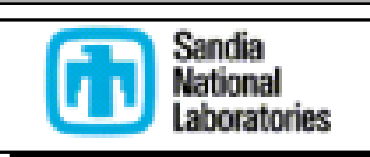 \\
\hline James Ross, J.T. Heineck, Steve Walker & 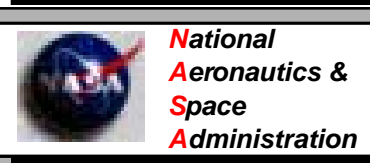 \\
\hline Fred Browand, Diego Arcas, Dennis Plocher & \begin{tabular}{c|c} 
USC & UNIVERSITY \\
(19) & OF SOUTHERN \\
CALIFORNA
\end{tabular} \\
\hline Anthony Leonard, Mike Rubel, Philippe Chatelain & (4) Caltech \\
\hline
\end{tabular}

Robert Englar

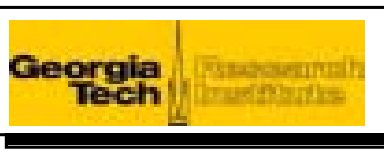

David Pointer, Tanju Sofu

David Whitfield

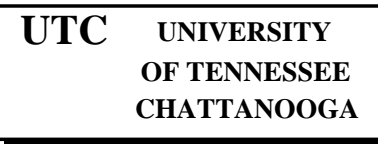

*Work performed under the auspices of the U.S. Department of Energy by the University of California, Lawrence Livermore National Laboratory under Contract W-7405-ENG-48. 


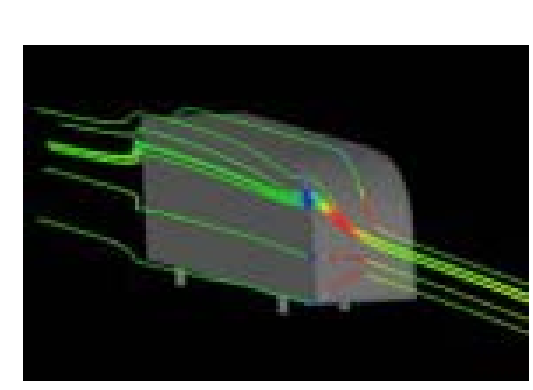

LLNL, SNL, ANL, Caltech, UTC

High quality numerical computations Guidance on computational tools

USC, NASA, LLNL, SNL

Comparisons and analyses

Insight into flow phenomena

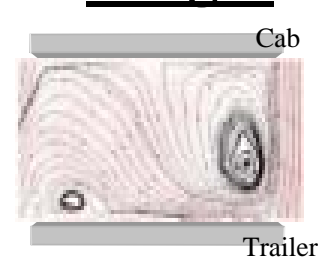

FREIGHTLINER

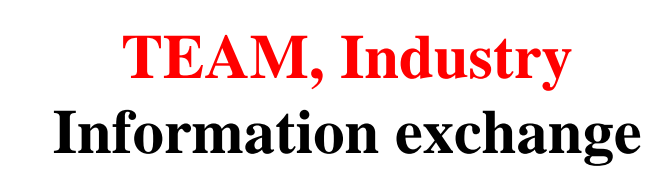

PACOAR inc

VOITO

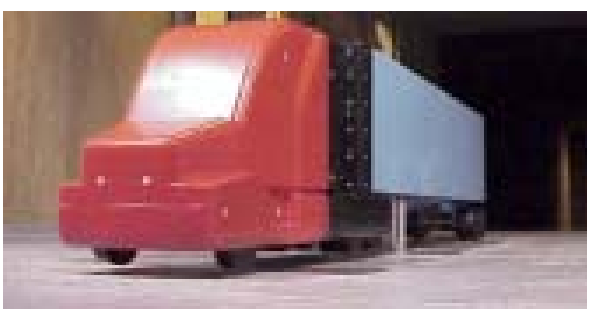

NASA, USC

Data base of high quality wind tunnel experiments

USC, GTRI, LLNL

Concepts and designs of aero devices
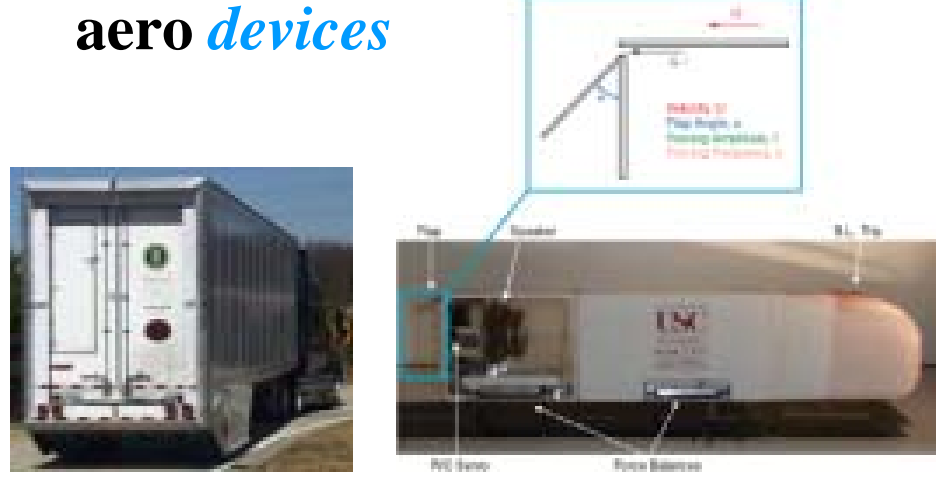

INDUSTRY SUPPORT

NEAR-TERM BENEFIT 


\title{
Accomplishments
}

\author{
Jim Ross \\ Heavy Vehicle Aerodynamic Drag Working Group Meeting \\ July 1, 2004
}




\section{Heavy Vehicle Drag Reduction Program Management Accomplishments}

- Kudos to Sid and Jules for keeping the program alive in turbulent times

- Rose too, for keeping everyone working toward the goals 


\section{Heavy Vehicle Drag Reduction Program Accomplishments}

- Drag-Reduction Concepts Tested/Developed

- Significant drag reduction documented for variety of devices (up to 20\%)

- Experiments

- Provided CFD validation data and guidelines for testing

- Improved understanding of flow physics

- On-the-road tests

- Computational Modeling

- Validation of variety of codes/turbulence models and guidance on modeling

- Improved understanding of flow physics

- Collaborations with Industry 


\section{Drag-Reduction Devices}

- Gap flow control

- Cab side extenders - reduced drag at yaw

- Gap stabilizer - similar effect

- Base-drag reduction

- Offset boat-tail plates

- Angled boat-tail plates (5-6\% fuel efficiency improvement)

- Coanda blowing (5\% fuel

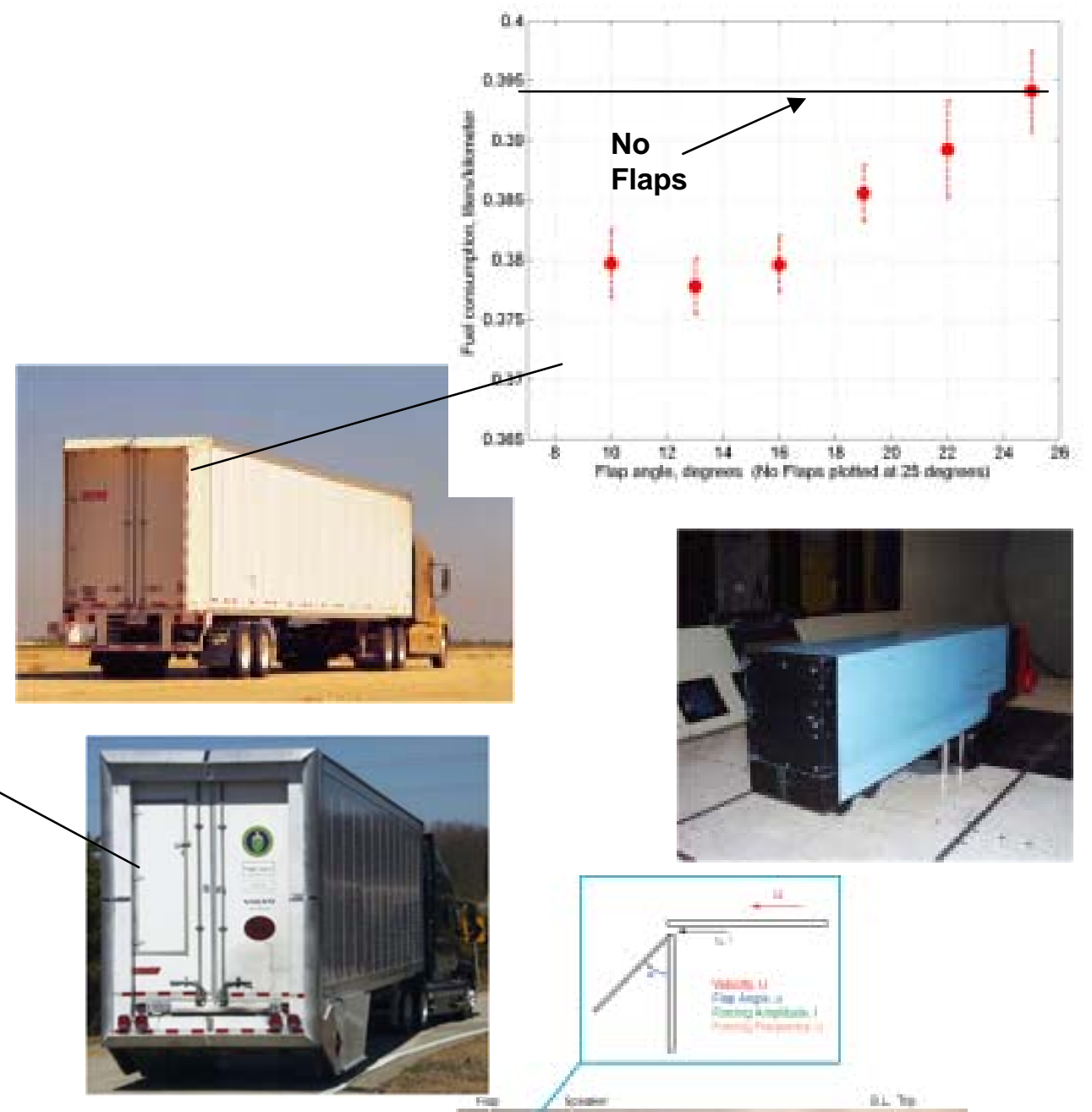

- Underbody flow control

- Trailer bogey wedge/fairing ( $\mathrm{x} \%$ efficiency gain)

- Trailer skirts (x\% gain)

- Belly box trailer (x\% gain)

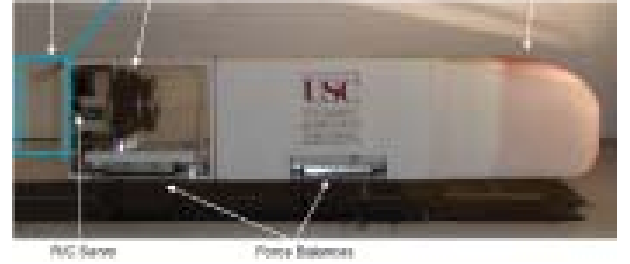




\section{Experiments}

- CFD Validation Cases

- GTS model Re $=0.5-2 \mathrm{M}$

- $\mathrm{GCM} \operatorname{Re}=0.5-6 \mathrm{M}$

- Flow Physics

- Corner radius

- Gap flow

- Test techniques

- Critical corner-radius Re

- Scale effects

- Importance of geometric fidelity on base-drag reduction

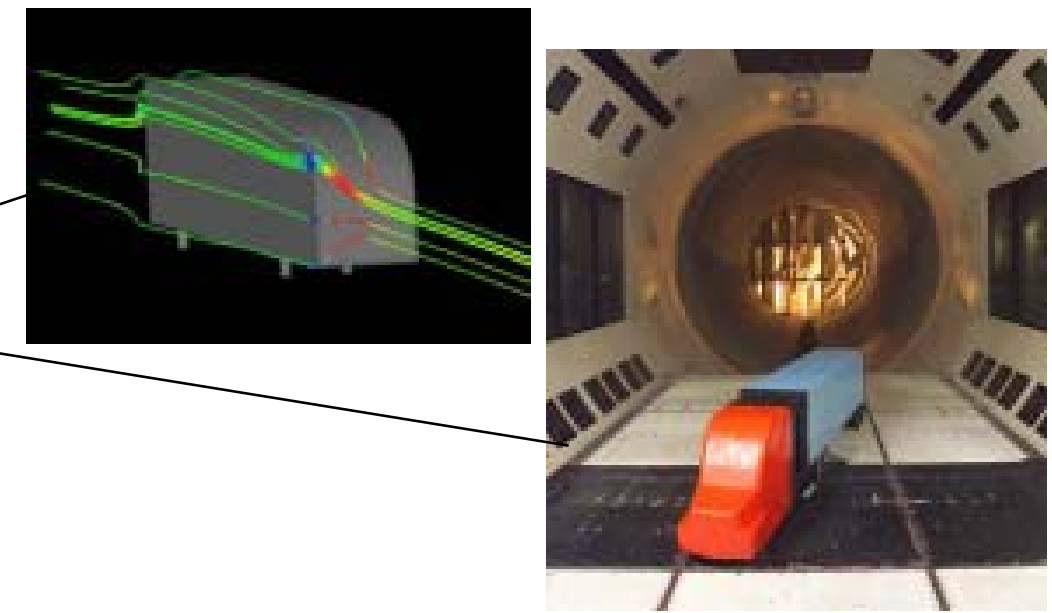




\section{Computational Modeling}

- Government codes

- SACCARA

- Overflow

- Commercial codes

- STAR-CD

- New methods

- LES

- Vortex method

- Modeling guidelines

- Grid refinement studies

- Turbulence model is important

- Can get good drag prediction and still miss flow features (e.g. wake structure) - why? 


\section{Collaborations}

- GTRI/Volvo - Coanda blowing road tests

- USC/Michelin - Splash \& spray studies

- USC/Maka/Wabash - Angled boat-tail plates

- Clarkson College/? - Angled boat-tail plates

- Argonne/PACCAR - Commercial CFD validation

- NASA/Freightliner - Wind-tunnel design

- UEF conference 


\title{
Issues
}

\author{
Kambiz Salari
}

Heavy Vehicle Aerodynamic Drag Working Group Meeting

July 1, 2004 
Adequately capture reality for design guidance of heavy vehicles and aero-devices

- Model scales

- Ground motion

- Model fidelity

- Engine flow

- Underbody

- Accessories

- Operational environment 


\section{Model fidelity}

- Ground Transportation System (GTS)

- Simplified tractor-trailer geometry

- Extremely useful in validation of computational models

- Generic Conventional Model (GCM)

- More representative of a modern tractor-trailer geometry

- Aero-devices could be tested

- To better understand the realistic performance of aero-devices, we should include

- Wheel wells, wheel rotation, and realistic tires

- Flow through engine

- More realistic underbody 


\section{Operational environment}

- NASA Ames and USC 3'x4' wind tunnel testing of the modified GTS model ( $1 / 16^{\text {th }}$ scale)

- Reynolds number attained is about 300 million, based on trailer width

- Higher Reynolds numbers are needed to understand the realistic performance of aero-devices

- NASA Ames 7'x10' wind tunnel testing of GCM (1/8 ${ }^{\text {th }}$ scale $)$

- Reynolds number attained is about 2 million, based on trailer width

- Moving ground plane should be added to understand the realistic performance of aero-devices

- NASA Ames12' pressure wind tunnel

- Full-scale Reynolds number is achieved!

- Similar to 7x10 wind tunnel, moving ground plane can improve our understanding of realistic performance of aero-devices

- Computational modeling and simulation

- Moving ground plane and realistic inflow conditions are needed to improve the predictive capability of computer models 
Getting drag reducing aero-devices on the road

- Full-scale testing

Track testing

Road testing 


\title{
Path Forward
}

\author{
Rose McCallen
}

Heavy Vehicle Aerodynamic Drag Working Group Meeting

July 1, 2004 


\section{FY05 plans address issues and push into new areas for big impact}

Adequately capture reality for design guidance of vehicle and aero devices

Full-scale track and road testing of devices

Further insight into flow phenomena and design optimization through computations of full vehicle

Experimental \& computational investigations of stationary road, moving truck, and rotating wheels

Investigate significance of operational environment

Get drag reducing technology on the road

Working meetings with industry to solicit input and feedback

Seek collaborative efforts with industry

Expansion into new areas

HV System Integration

Safety

External aero for brake \& engine cooling

Railcars

Splash \& spray mitigation

Commercial airlines Aerodynamic coal cars

Drag reduction through computational modeling 


\section{Capturing reality through full-scale testing and complimentary experiments/computations}

\section{Model scale and fidelity}

Track/road testing of angled plates, V-Shield, and gap stabilizer

Track testing of pneumatic devices

Analysis, model validation using 12-ft PWT data ...full scale Re !

Unsteady RANS, hybrid RANS/LES to capture base/gap flow and flow

with side winds

Ground motion

Computationally modeling

stationary road

moving truck

rotating wheels

to determine impact on underbody and base drag devices

Operational environment

Continue investigation of device performance with side wind

Project effect of weather on aero drag 


\section{Leveraging: Further fuel savings can be recognized and vehicle safety enhanced}

Experimental and computational investigations

HV System Integration

Modeling flow around rotating wheels for impact on Brake cooling

Underbody \& base drag aero devices

Safety:

Modeling sheeting and drop formation for splash \& spray

Railcars:

Determining concepts for reducing drag with empty coal cars

Commercial airlines seeking assistance

Provide data and collaborate on computational effort e.g., data/computations for bimodal flow in tractor/trailer gap provides desired test case for model validation
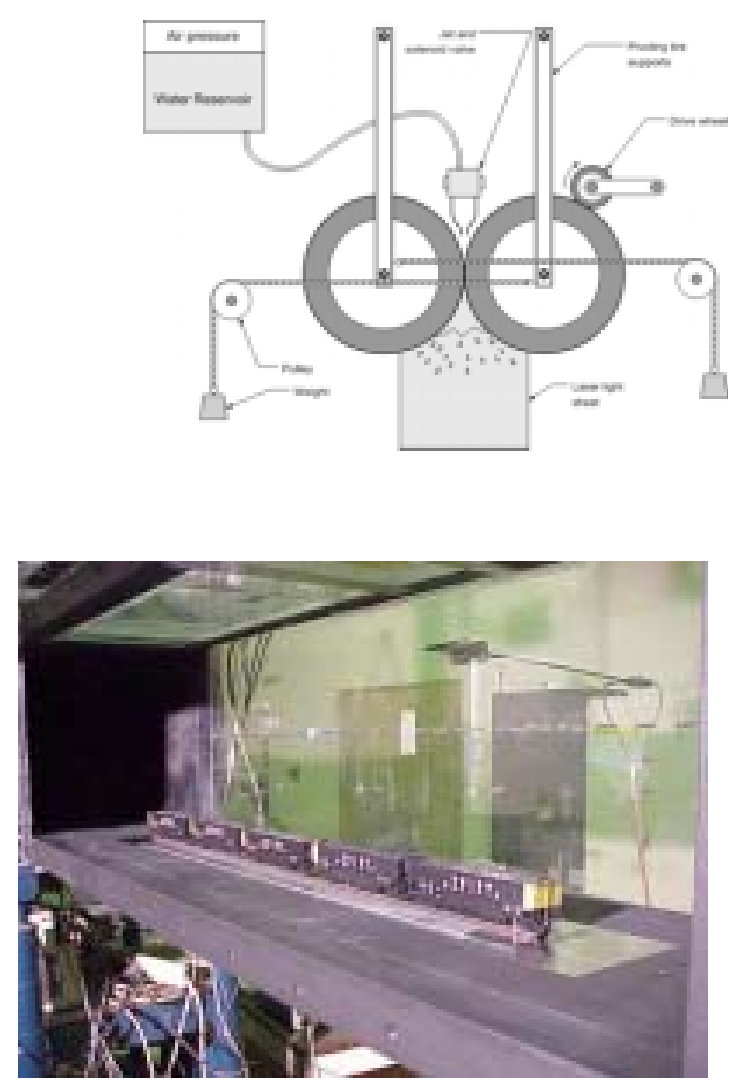

\begin{tabular}{|l|l|l|l|}
\hline Yaw, deg & Cd empty & Cd full & \%diff \\
\hline 0 & 0.315 & 0.216 & 32 \\
\hline 10 & 0.519 & 0.300 & 42 \\
\hline
\end{tabular}




\title{
Path Forward A Brief Summary
}

Heavy Vehicle Aerodynamic Drag Working Group Meeting

\author{
Portland, OR
}

July 1, 2004 


\section{Addressing Issues and Moving Into New Areas}

- Full scale testing

- TRC vs Crow's Landing

- Fidelity

- URANS and DES

- Consider 12' Pressurized Tunnel Experiments

- Ground Motion and Rotating Wheels

- Splash and Spray

- Heavy vehicle system integration

- Other systems

- Railcars

- Aircraft (high load, high lift vehicles) 


\section{Full Scale Experiments}

- TRC

- Would prefer SAE Test (TOO COSTLY)

- Next preference would be coastdown tests

- Do not trust broadcast fuel rates

- OEM's

- Would prefer coastdown tests

- Broadcast fuel rate tests OK for scoping

- May prefer long road tests to capture wind effects

- NEED BOTH CONTROLLED TESTS AND LONG ROAD TESTS

- At least $65 \mathrm{mph}$ 


\section{Fidelity}

- Are showing that both URANS and DES can capture primary flow features

- Need further assessment of

- grid sensitivity

- Sensitivity to stiffness of inlet condition

- Sensitivity to development length for boundary layer

- OEM's

- Need to focus on practical methods for near-term application

- Consider multiple commercial codes if possible

- NEED TO DO BOTH

- Support use of CFD by OEM's

- Use advanced methods to understand physics

- Further develop and validate advanced methods for mid- to far-term use by OEM's 


\section{Are we on the right path?}

- Focusing on device development

- Should we be looking at

- Integrated analysis?

- Underhood and external aero

- Rotating wheels?

- Splash and spray

- Aeroacoustics? 


\section{Summary}

- $\quad$ OEM's needs guidance on submitted proposals; need $\$ \$ \$$

- $\quad$ Consortium needs a quick and dirty means of testing drag reduction devices on the road/track

- Crow's Landing => positive response

- Need to include fleet organizations

- continue inviting them until they attend working meetings

- $\quad$ attend meetings of the ATA, TMA, TMC

- present results for "educational" instruction

- Trailer manufacturers will not implement trailer drag reduction devices until fleets begin using or demanding them

- DOE can't be a "certifying agency"

- "Product development" (durability, lifecycle cost, maintenance, weather issues...) on the drag reduction devices needs to begin

- What is the way to get the drag reduction devices on the road?

- Education of fleets 


\section{Summary}

- What results will convince the OEM/fleets/trailer manufacturers of the effectiveness of the drag reduction devices?

- $\quad$ clear cost estimates, drag reduction capability, e.g. Crow's Landing

- demonstration with a fleet, e.g. APU unit demo

- $\quad$ Need to select one of these drag reduction devices that we know works and move forward to getting it on the road

- $\quad$ e.g. USC/MAKA/Wabash at Crow's Landing

- Consortium can act as a clearinghouse

- CFD, experimental testing of devices

- $\quad$ OEM's can give input on the drag reduction devices

- $\quad$ Factors to include in future tests

- $\quad$ Priority driven by emission requirements

- $\quad$ engine flow for cooling

- underbody (easier)

- $\quad$ rotating wheels ("OEM's know quite a bit)

- Re effects with high fidelity

- Regulatory issues

- e.g. bumper rule, length restriction, lower speed, emission requirements Back to integration

- $\quad$ Engine cooling, trailer drag, external aerodynamics... 


\section{Hubbert's Peak: When will world oil production peak?}

This presentation is based almost entirely upon material from the book by Kenneth Deffeyes entitled: "Hubbert's Peak: The Impending World Oil Shortage", Princeton University press, 2001, ISBN 0-691-09086-6

I recommend the book highly. What follows is my interpretation of the gist of Deffeye's (and Hubbert's) argument.

"In 1956, the geologist M. King Hubbert predicted that U.S. oil production would peak in the early 1970's. Almost everyone, inside and outside the oil industry, rejected Hubbert's analysis. The controversy raged until 1970, when U.S. production of crude oil started to fall. Hubbert was right." (Deffeyes, page 1) 


\section{Hubbert's Peak: \\ When will world oil production peak?}

"Hubbert made his 1956 prediction at a meeting of the American Petroleum Institute in San Antonio, where he predicted that U.S. oil production would peak in the early 1970s. He said later that the Shell Oil head office was on the phone right down to the last five minutes before the talk, asking Hubbert to withdraw his prediction. Hubbert had an exceedingly combative personality, and he went through with his announcement." (page 2)

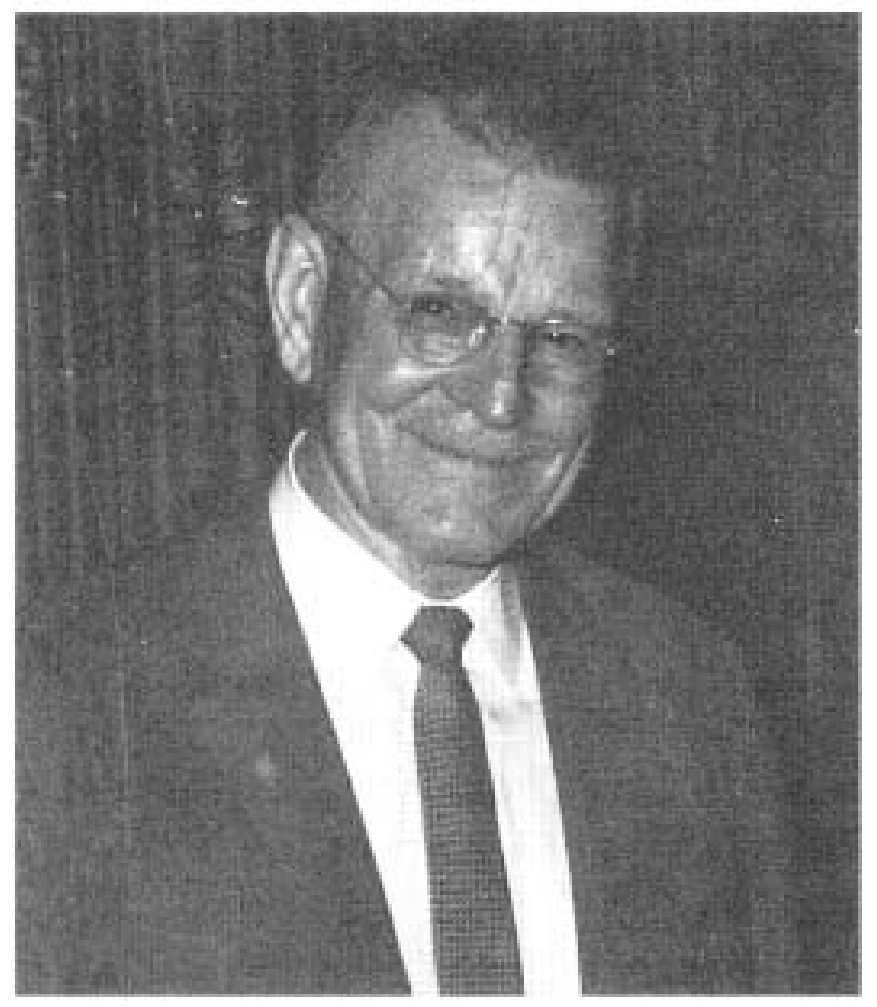




\section{Hubbert's Peak: When will world oil production peak?}

Cumulative production of an expendable resource must look like this:

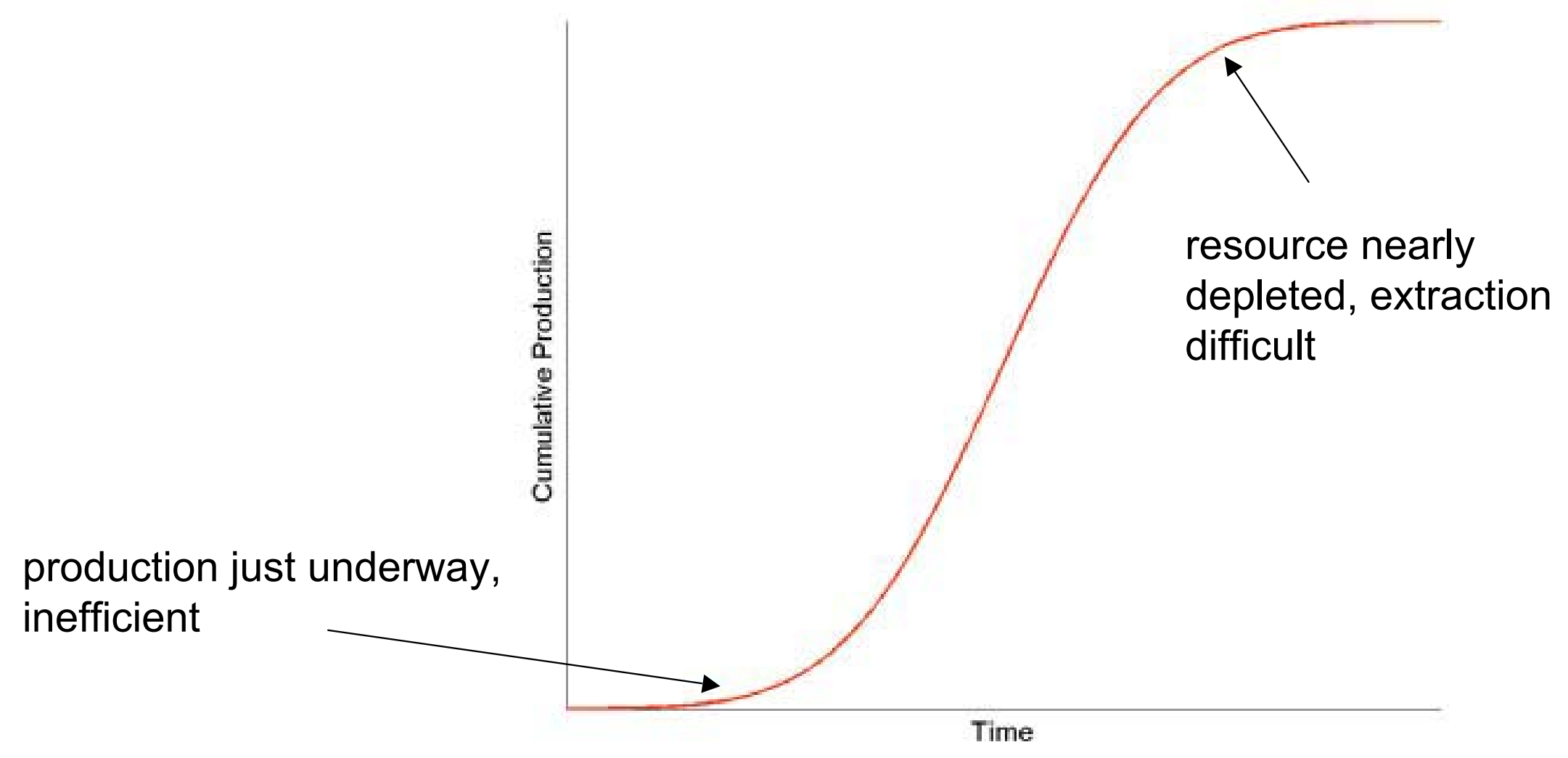




\section{Hubbert's Peak: When will world oil production peak?}

Implication:

Peak production occurs near center of resource use

(for a symmetrical distribution, peak occurs at halfway point)

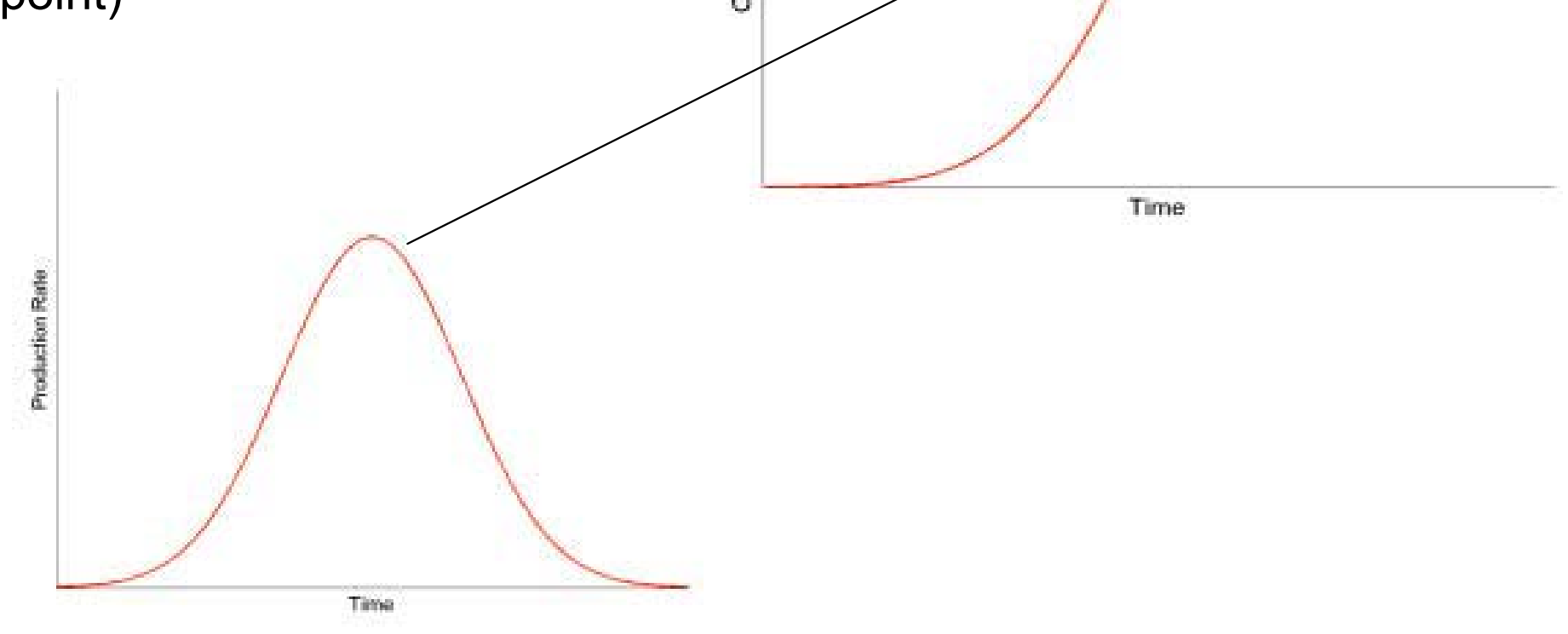




\section{Hubbert's Peak: \\ When will world oil production peak?}

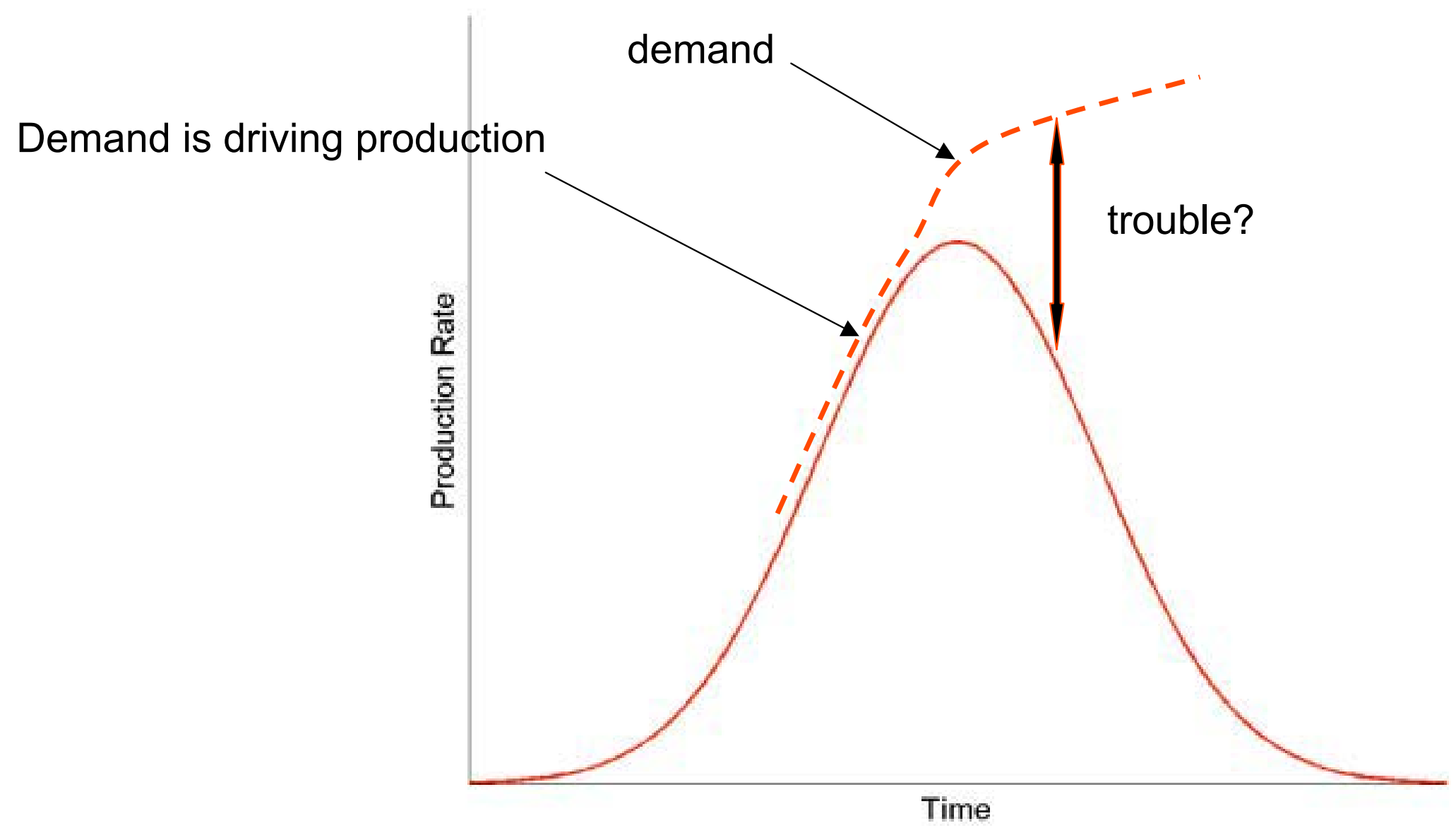




\section{Hubbert's Peak: \\ When will world oil production peak?}

All data in millions of barrels of oil annually

* Includes refined products

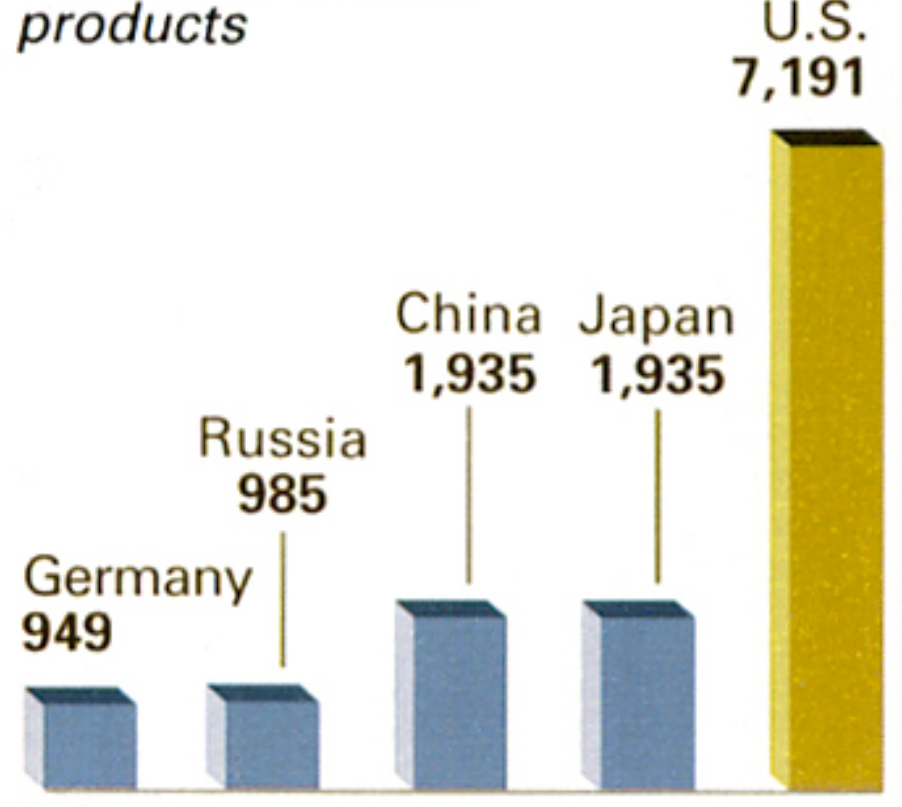

2002 Oil consumption

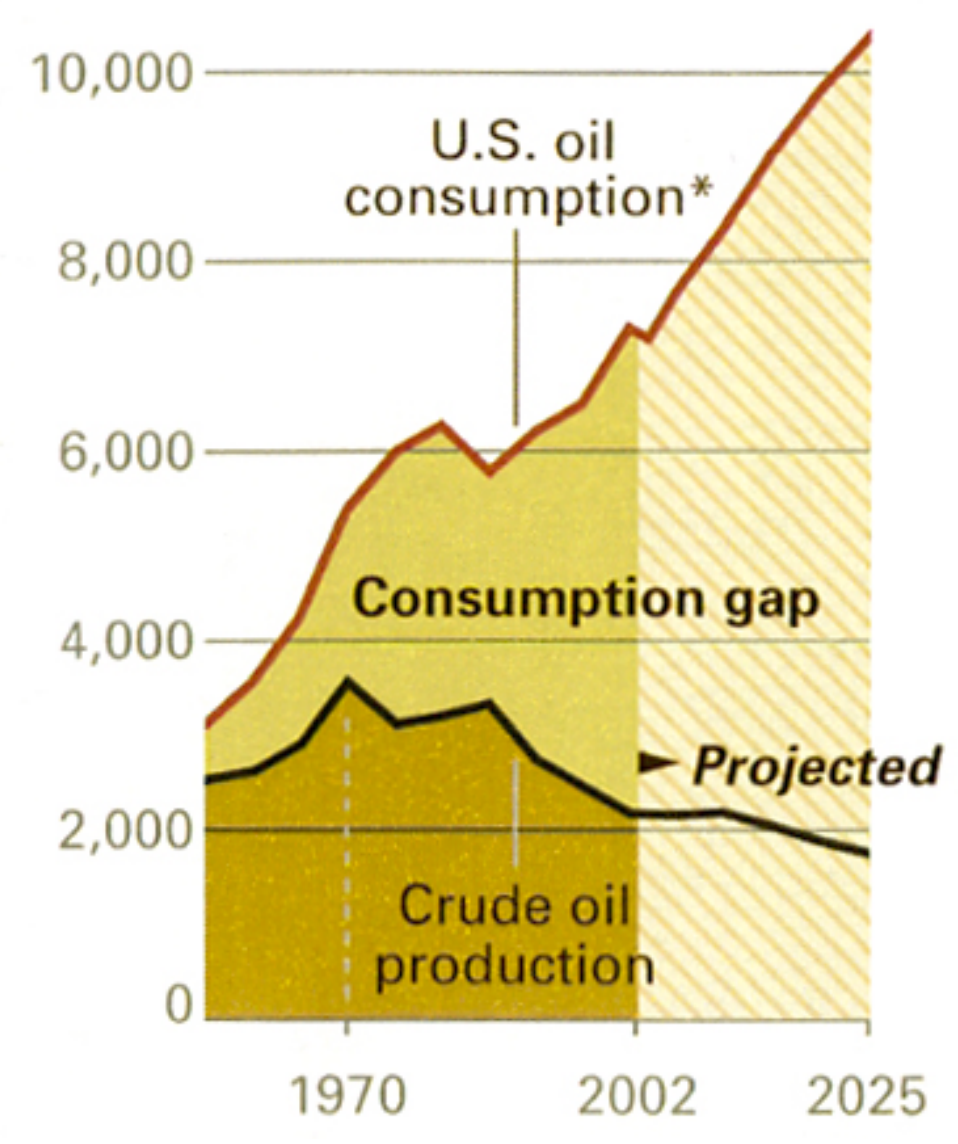

National Geographic, June 2004 


\section{Hubbert's Peak: \\ When will world oil production peak?}

"Hubbert's 1956 analysis tried out two different educated guesses for the amount of U.S. oil that would eventually be discovered and produced by conventional means: 150 billion and 200 billion barrels. He then made plausible estimates of future oil production rates for each of the two guesses. Even the most optimistic estimate, 200 billion barrels, led to a predicted peak of U.S. oil production in the early 1970s. The actual peak year turned out to be 1970." (page 4)

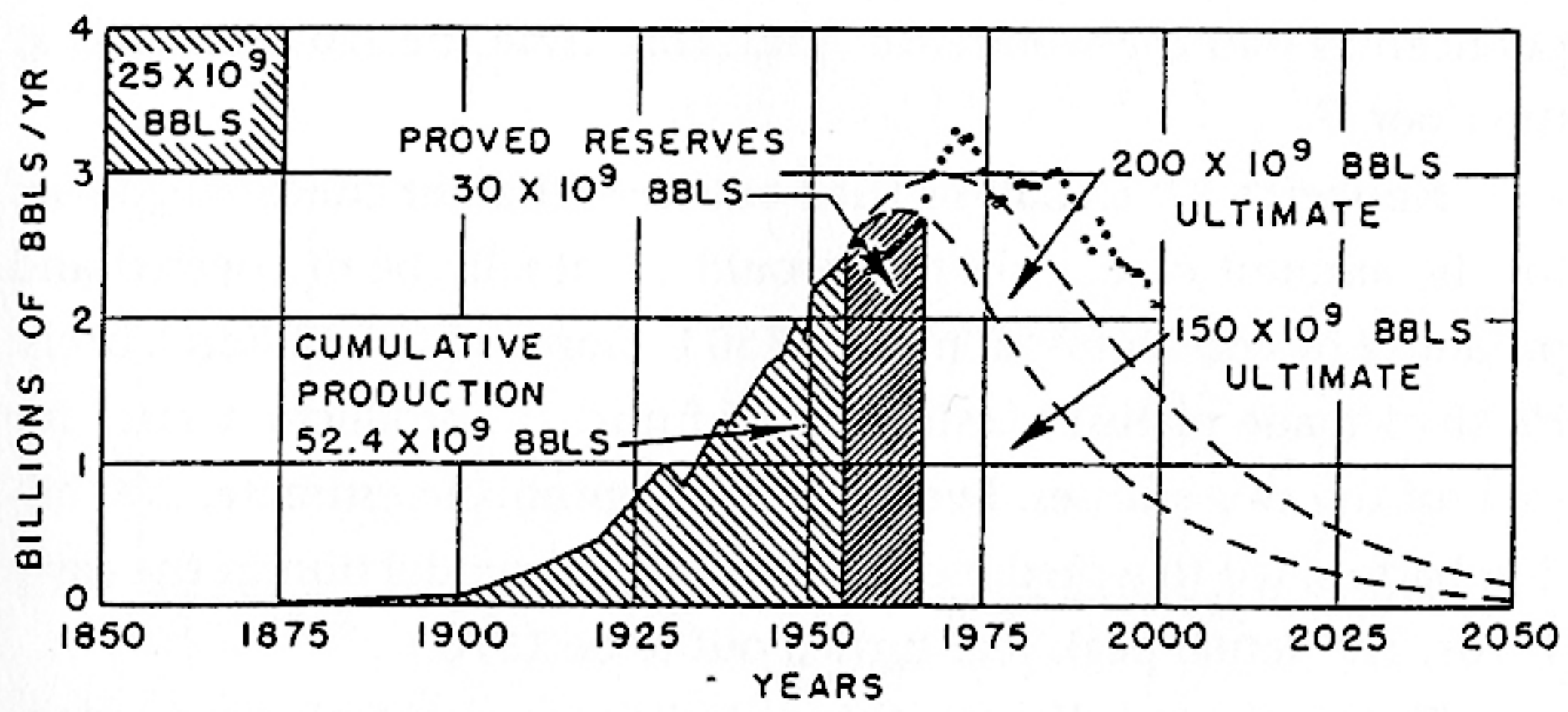




\section{Hubbert's Peak: When will world oil production peak?}

Deffeye's Gaussian fit to U.S. oil production

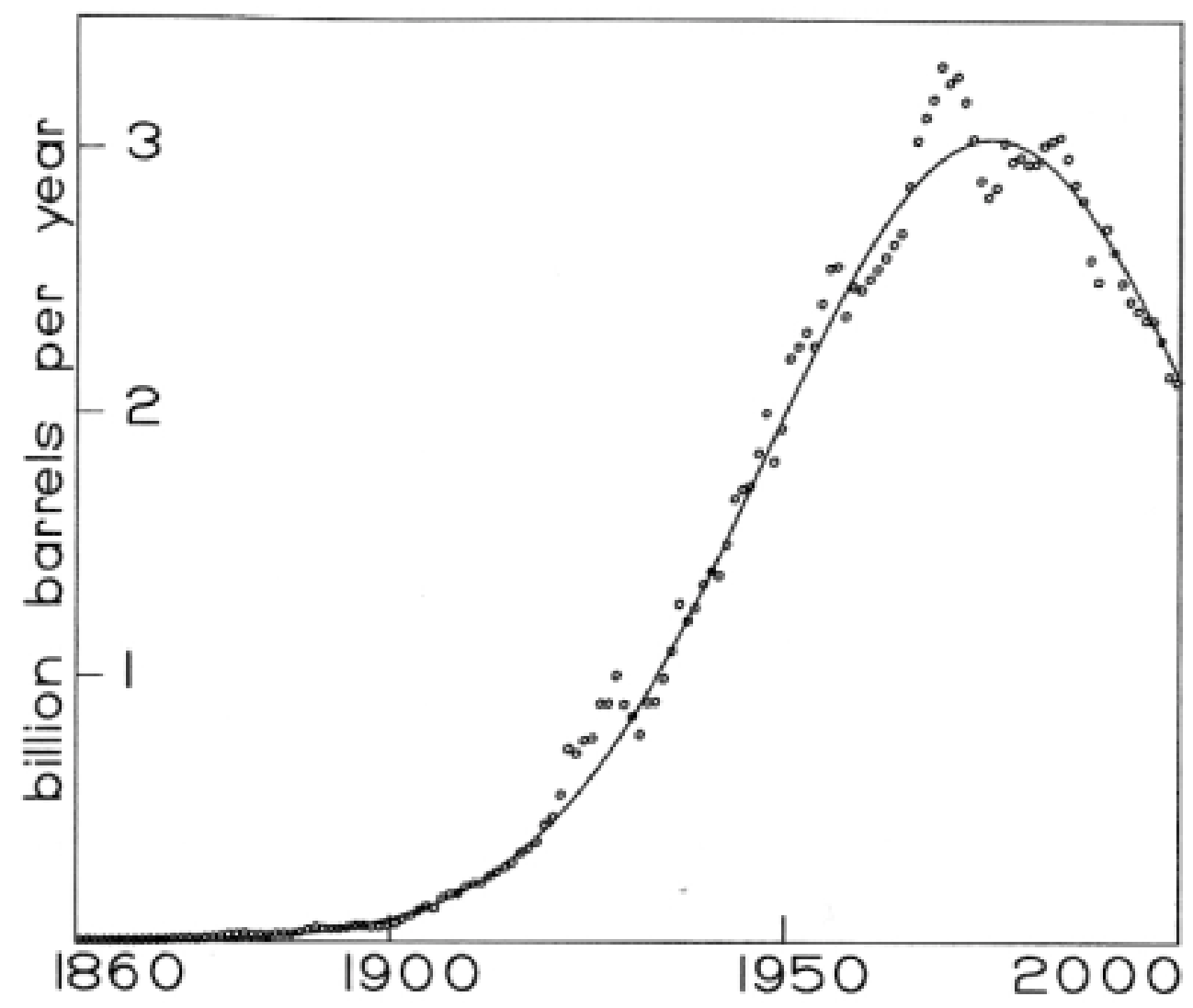

Annual production of U.S. crude oil (circles) with the best-fitting Gaussian curve superimposed as a solid line. Production from Alaska and from offshore oil fields is included. 


\section{Hubbert's Peak: \\ When will world oil production peak?}

"The great weakness of Hubbert's 1956 prediction was his reliance on educated estimates of the eventual total oil production. .... In 1962... Hubbert noticed that oil reserves were beginning to drop even though production was still rising."

..."Hubbert defined 'discovery' to be the cumulative production up to a given time plus the underground reserves known at that time. ... discovery leads production by about 11years" (page 144)

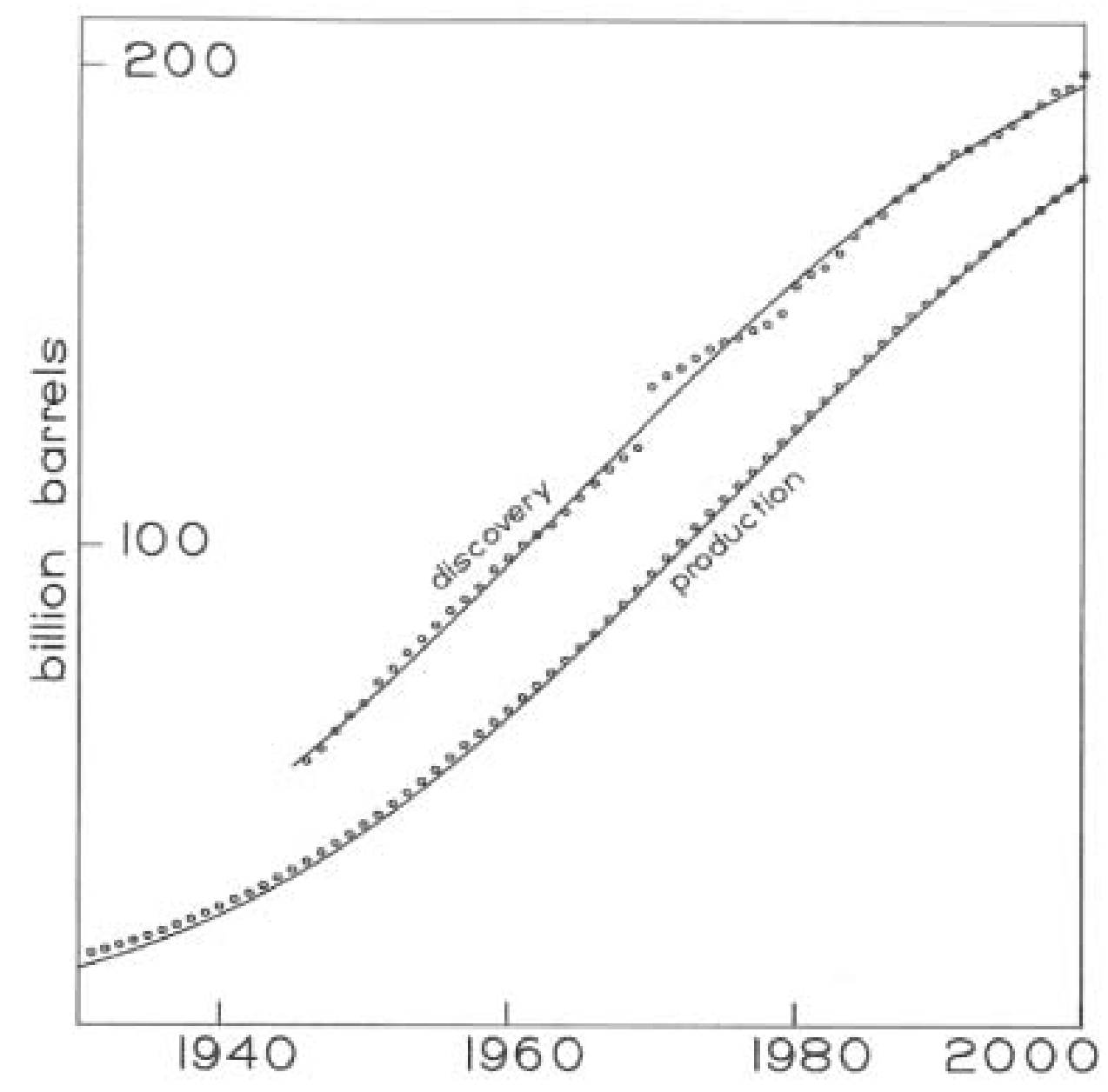




\section{Hubbert's Peak: \\ When will world oil production peak?}

Deffeye's rate plot for U.S.

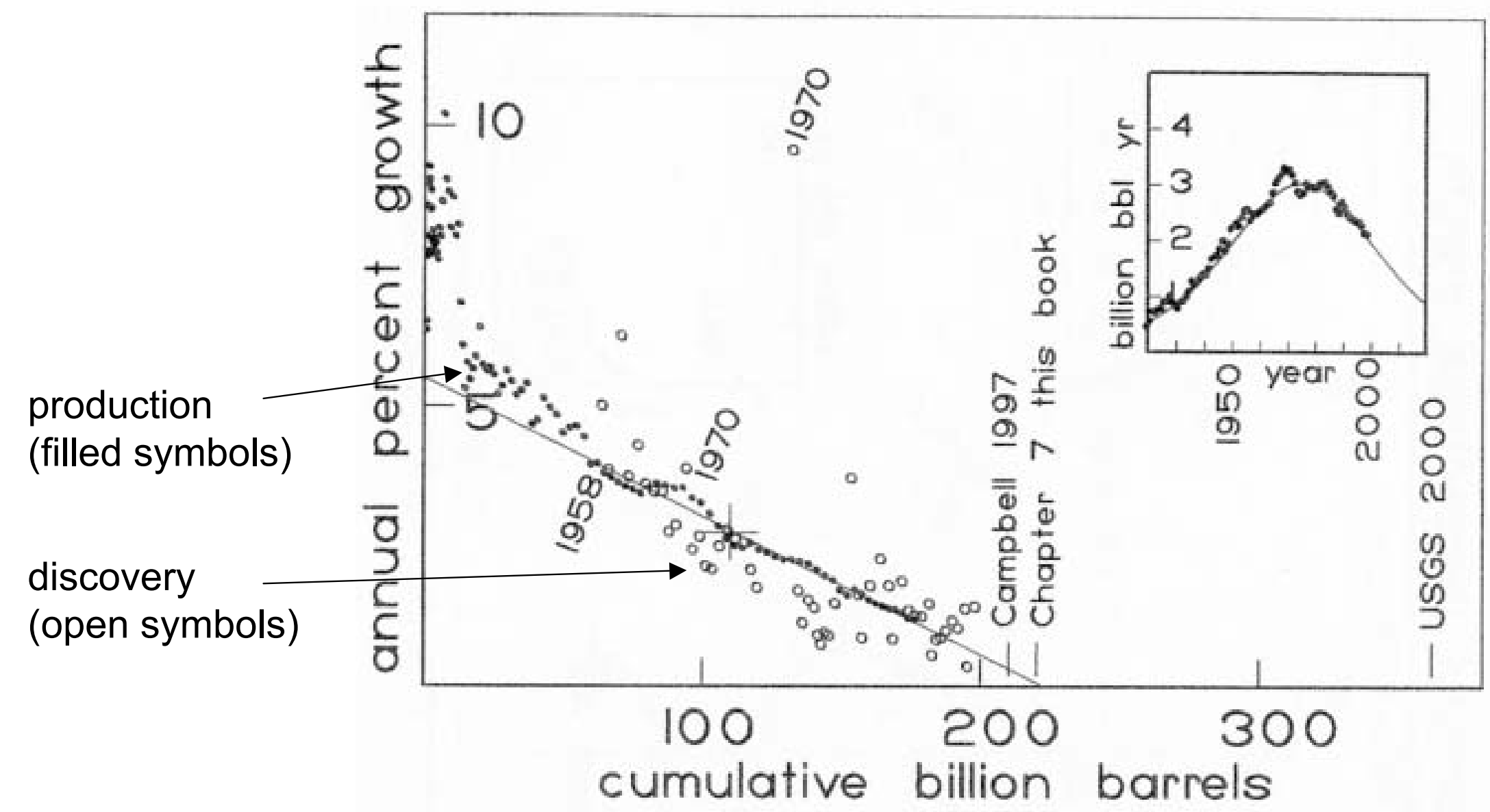




\section{Hubbert's Peak: \\ When will world oil production peak?}

Example: Gaussian model

$Q=Q_{o} / 2\left[1+\operatorname{erf}\left(\alpha\left(t-t_{o}\right)\right]\right.$

$Q_{0}=2 \cdot 10^{12}$ barrels

$\alpha=0.025$ per year

$\mathrm{t}_{\mathrm{o}}=0$
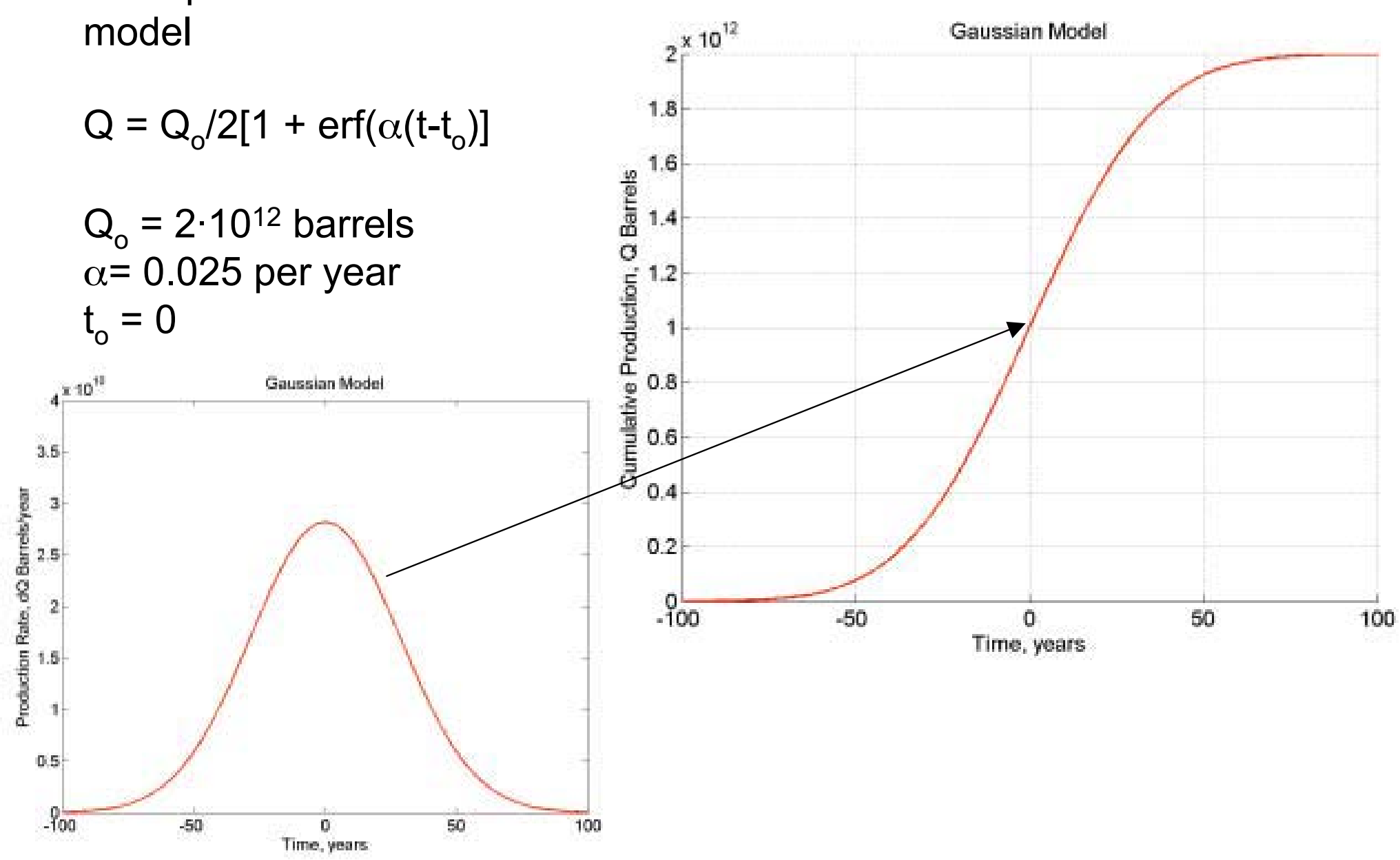


\section{Hubbert's Peak: \\ When will world oil production peak?}

Example: Gaussian model

Gaussian Model

$Q=Q_{o} / 2\left[1+\operatorname{erf}\left(\alpha\left(t-t_{0}\right)\right]\right.$

$Q_{0}=2 \cdot 10^{12}$ barrels

$\alpha=0.025$ per year

$\mathrm{t}_{\mathrm{o}}=0$

$t_{0}=0$.

$\mathrm{dQ} / \mathrm{Q} \approx 2 \alpha\left[1-\mathrm{Q} / \mathrm{Q}_{\mathrm{o}}\right]$

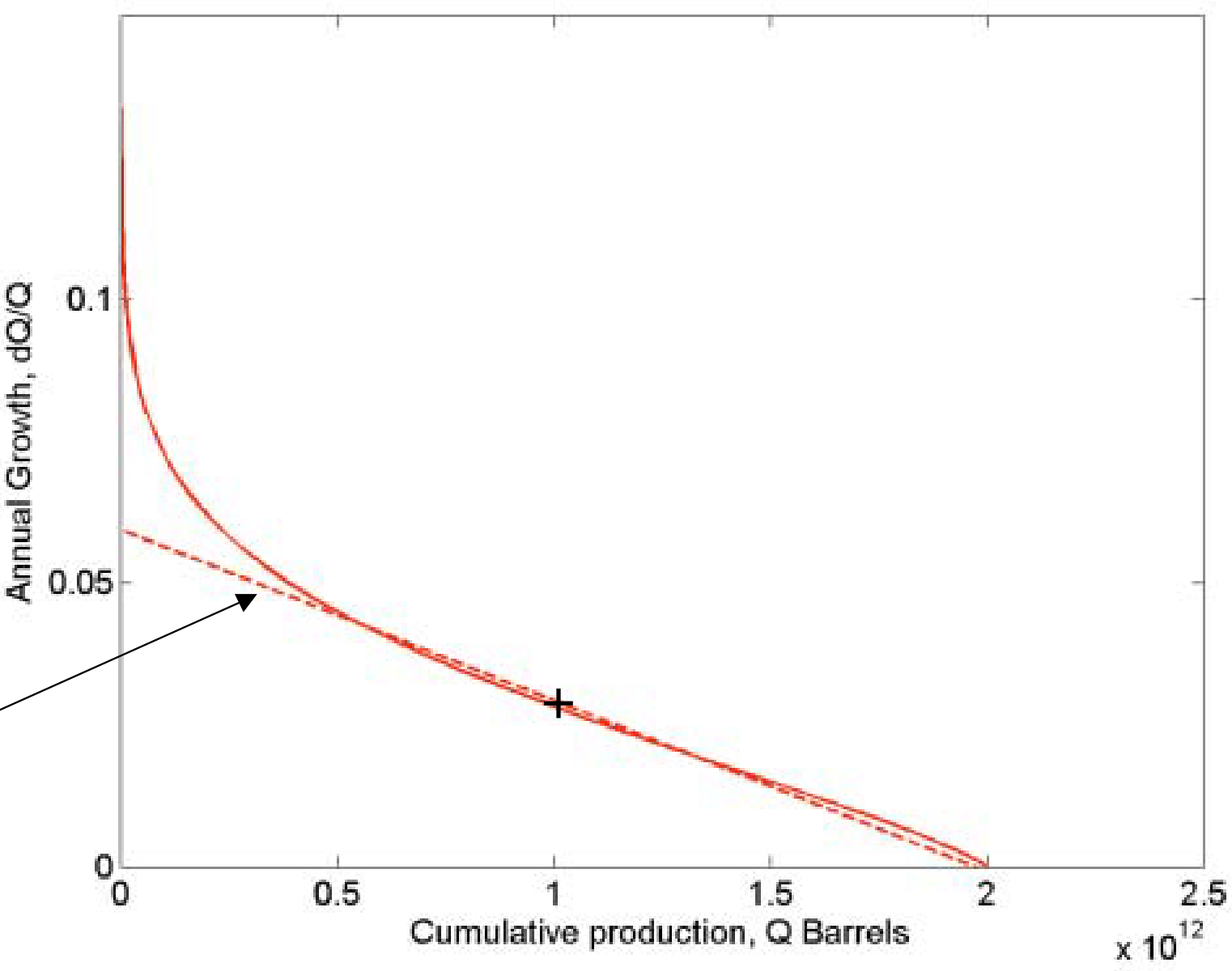




\section{Hubbert's Peak: When will world oil production peak?}

Deffeye's analysis of world oil production

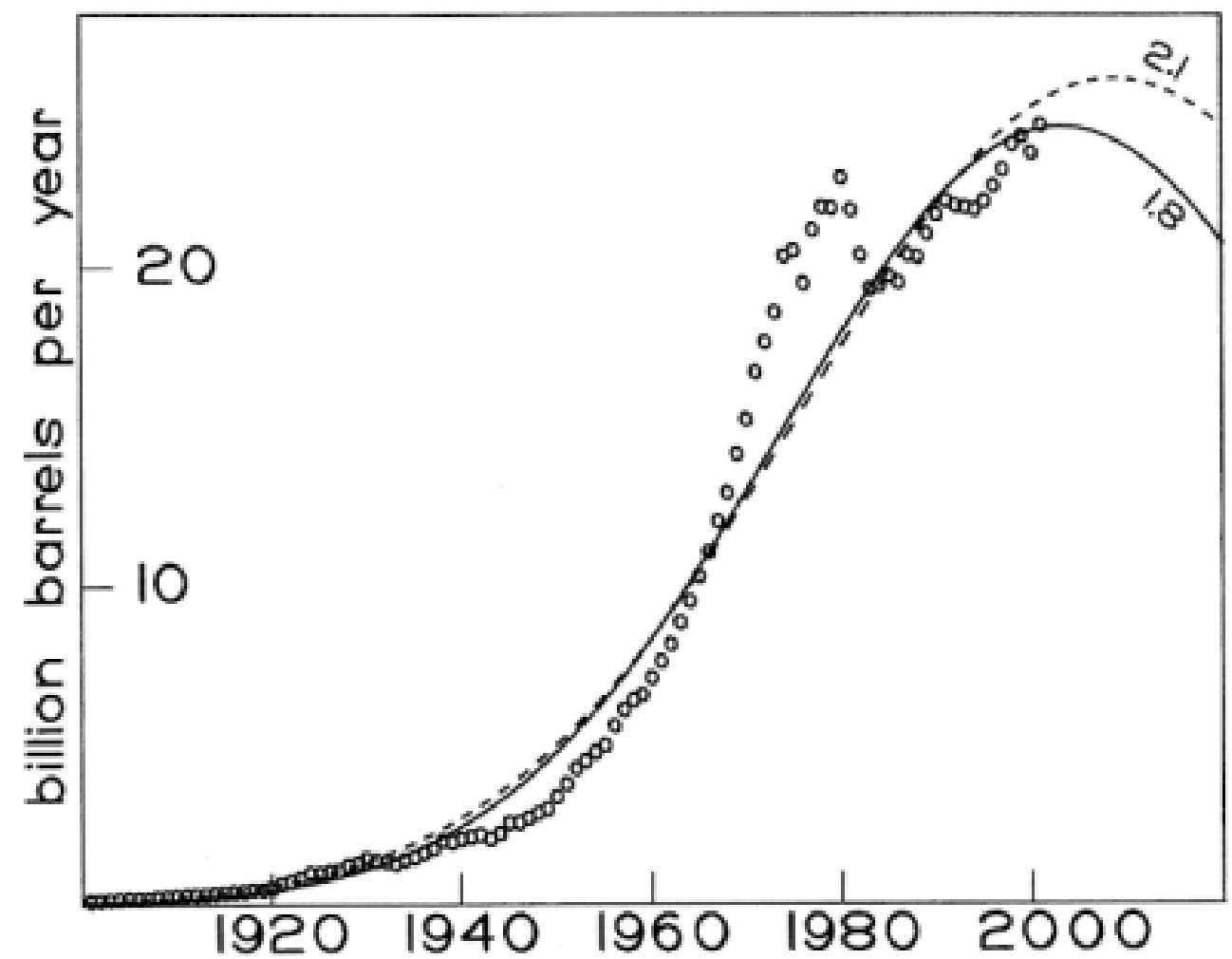

Annual production of world oil (circles), with Gaussian curves corresponding to total eventual oil recovery of 1.8 and 2.1 trillion barrels. A steeper rising curve with its top chopped off by market limitations would make a better fit. 


\section{Hubbert's Peak: When will world oil production peak?}

Deffeye's analysis of world oil production

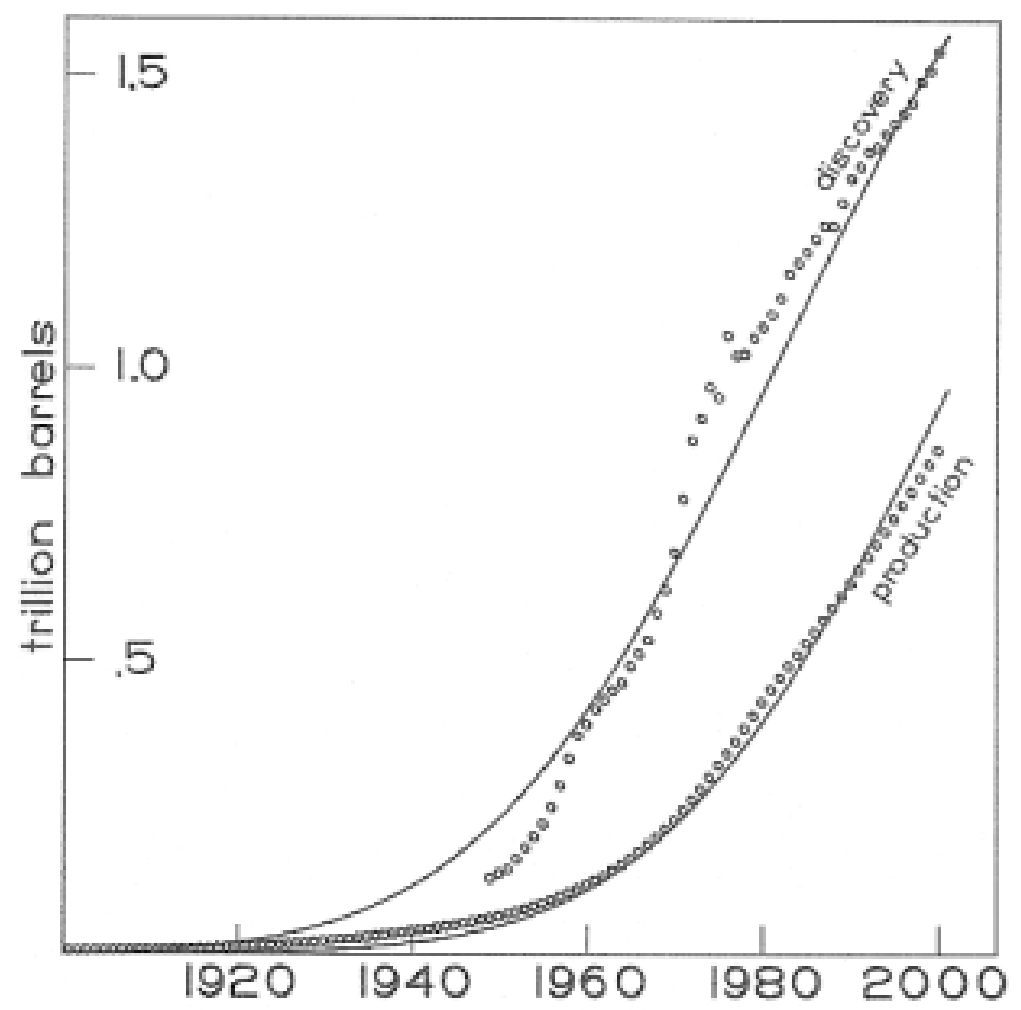

Cumulative world oil production and cumulative production plus reserves (discoveries) are compared with the best-fitting cumulative Gaussian curves. The two solid curves are constrained to have exactly the same shape but are displaced in time. No estimates are fed into the computer program that fits the curves to the data. The best-fitting estimate is for the year of maximum production to be 2003, and the eventual cumulative production is estimated at 2.12 trillion barrels. Discoveries lead production by 21 years. 


\section{Hubbert's Peak: \\ When will world oil production peak?}

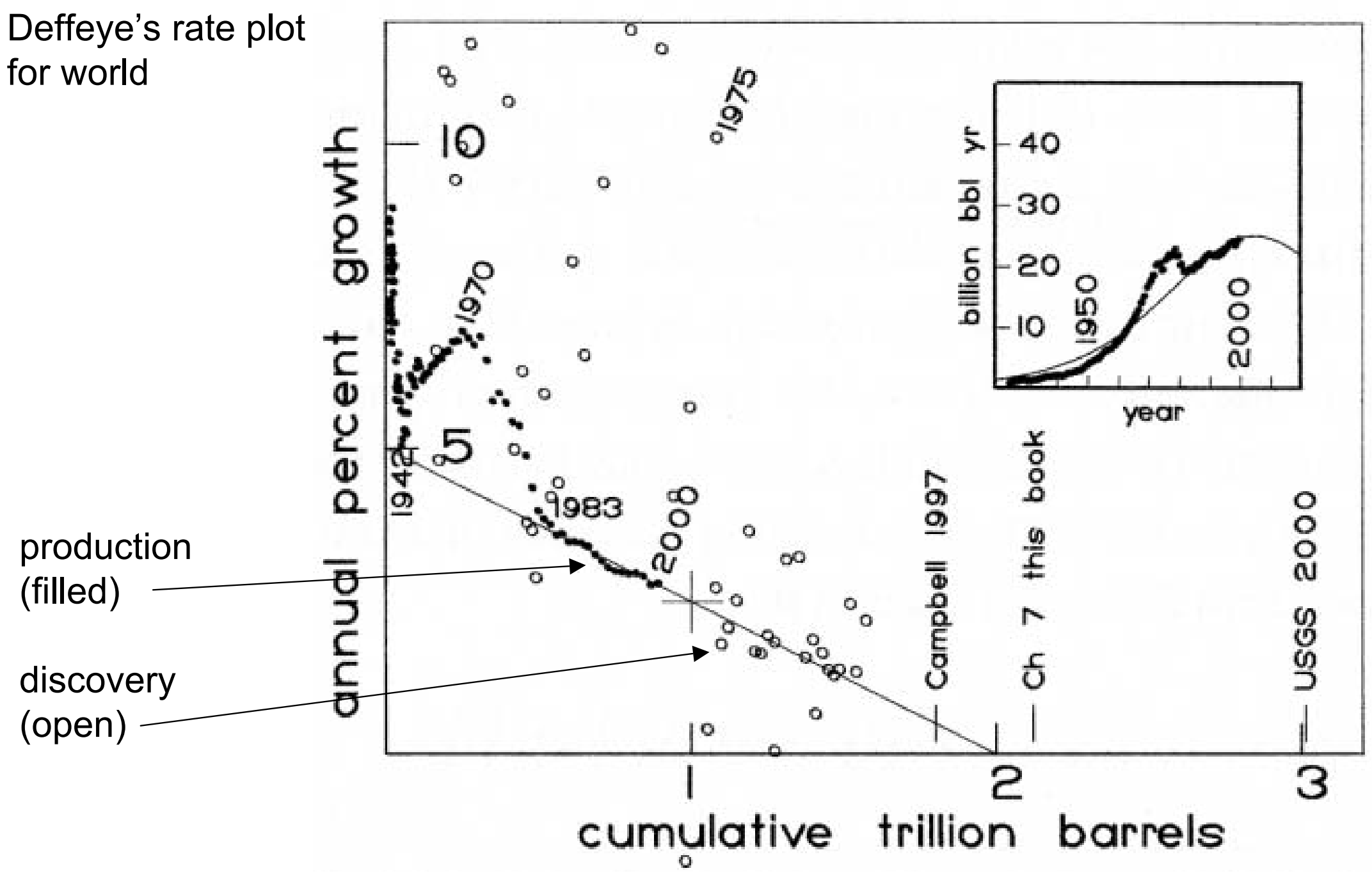




\section{Hubbert's Peak: \\ When will world oil production peak?}

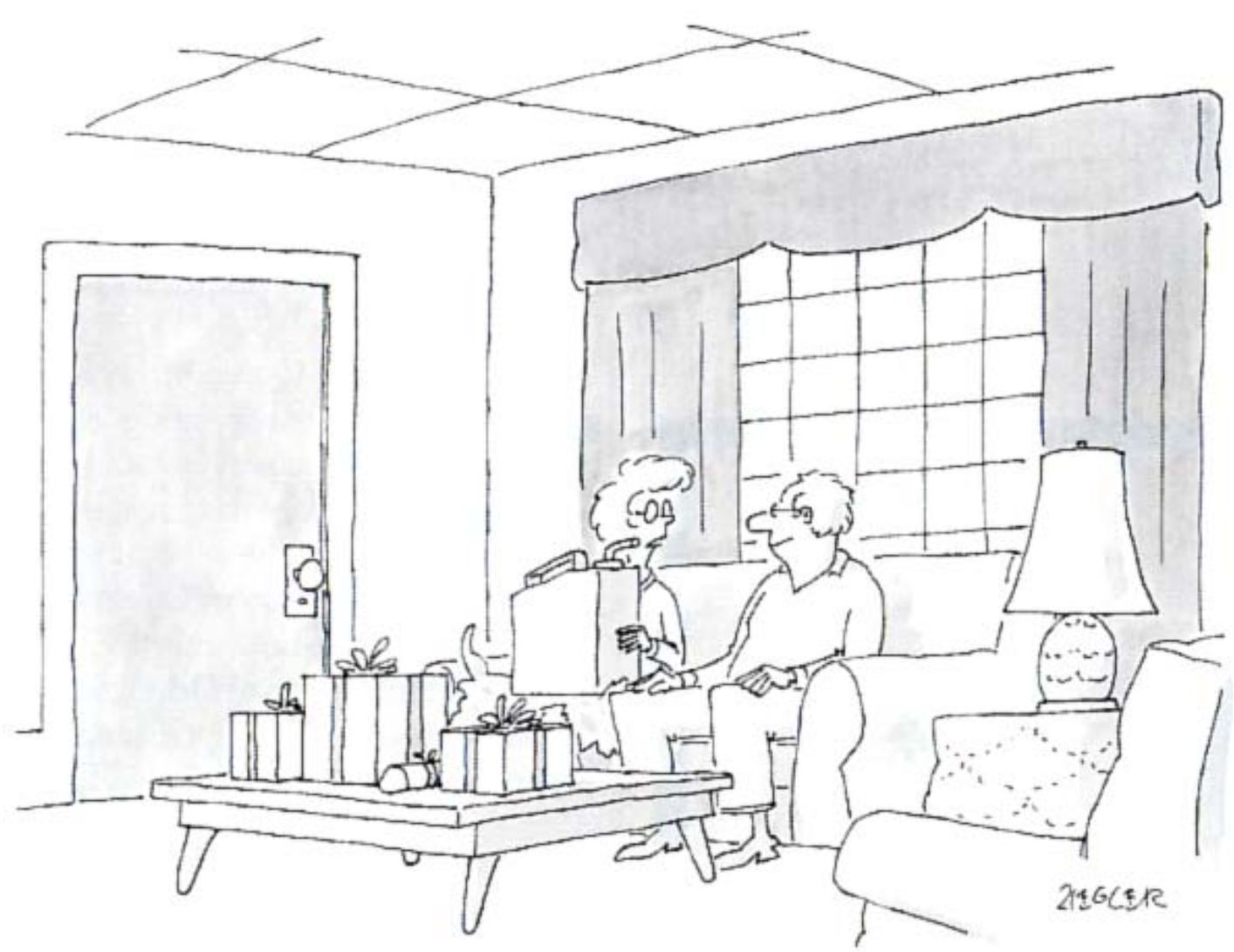

"Why, thank you, dear-I suppose five gallons of gas is a thoughtful birthday gift."

The New Yorker, June 14, 2004 


\section{Hubbert's Peak:}

When will world oil production peak?

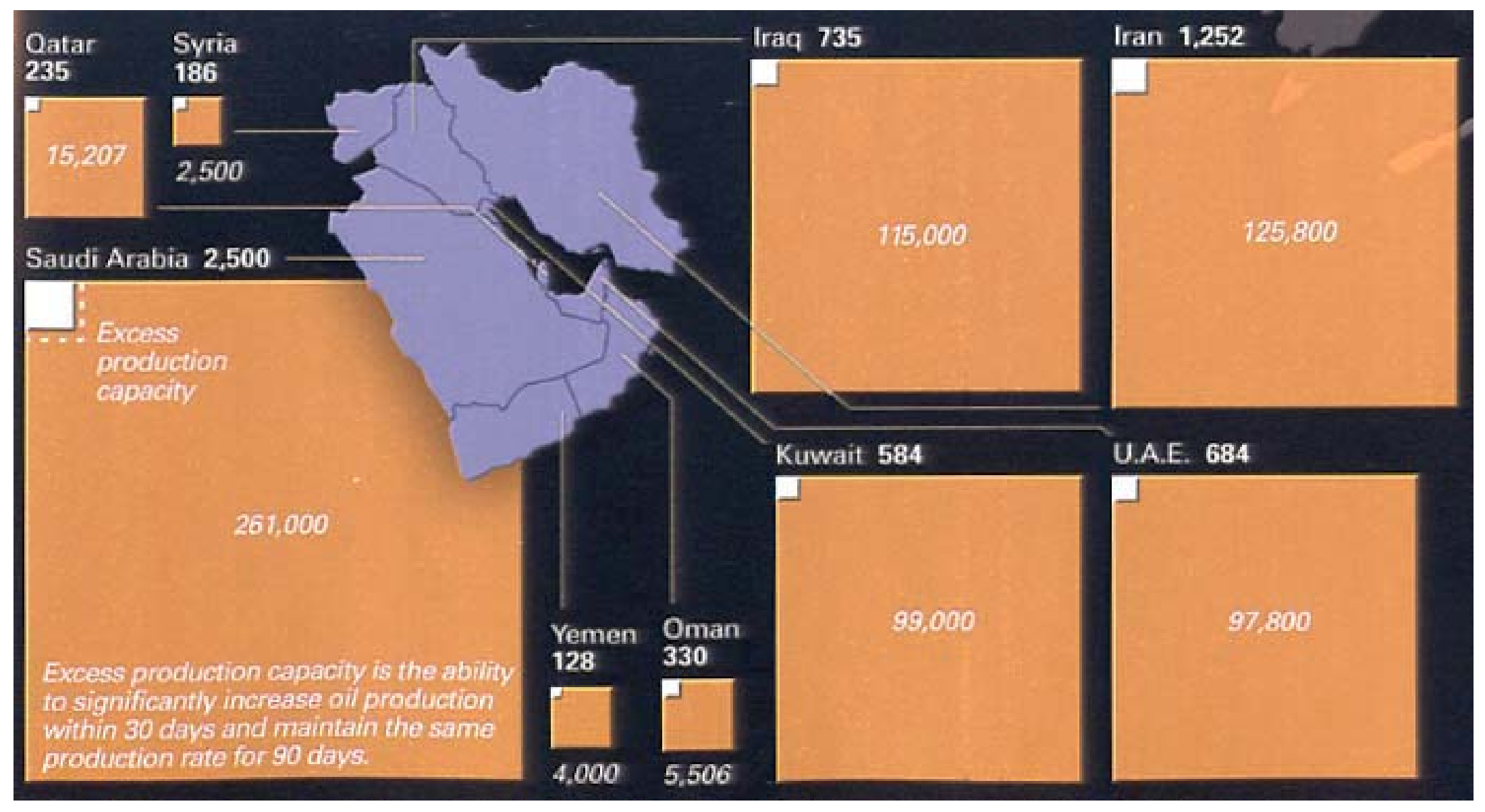

National Geographic, June 2004 